\title{
INFLUENCE OF CHELATING AGENTS ON PROTEOLYSIS OF MICELLAR CASEIN SLURRIES
}

\author{
A Thesis \\ presented to \\ the Faculty of California Polytechnic State University, \\ San Luis Obispo
}

\author{
In Partial Fulfillment \\ of the Requirements for the Degree \\ Master of Science in Agriculture \\ Specializing in: Dairy Products Technology
}

by

Azucena Becerril Díez

June 2016 
(C) 2016

Azucena Becerril Díez

ALL RIGHTS RESERVED 


\section{COMMITTEE MEMBERSHIP}

TITLE:

AUTHOR:

DATE SUBMITTED:

COMMITTEE CHAIR:

COMMITTEE MEMBER:

COMMITTEE MEMBER:
Influence of Chelating Agents on Proteolysis of Micellar Casein Slurries

Azucena Becerril Díez

June 2016

Vincent Yeung, Ph.D.

Professor of Dairy Science

John H. Walker, Ph.D.

Associate Professor of Statistics

Phillip S. Tong, Ph.D.

Professor of Dairy Science 


\author{
ABSTRACT \\ Influence of Chelating Agents on Proteolysis \\ of Micellar Casein Slurries \\ Azucena Becerril Díez
}

The focus of this research was to analyze the effect of $\mathrm{Ca}$ chelators on the proteolytic activity of rennet during ripening of a micellar casein slurry. This research was divided in two phases. During the first phase, preliminary studies were performed to understand the behavior of rennet and the milk system in the presence of chelating agents. A solution of reconstituted skim milk at $10 \%(\mathrm{w} / \mathrm{v})$ was prepared. Individual samples of this solution were divided in two study groups, samples with chelators and rennet and samples with only chelators. Two different chelators were used, sodium hexametaphosphate (SHMP or NaHMP) at concentration levels of 2.5 and $10 \mathrm{mM}$; and sodium citrate (SC) at concentration levels of 5 and $25 \mathrm{mM}$. These samples were incubated in a water bath at $32^{\circ} \mathrm{C}$ to measure coagulation time (CT) and Urea-PAGE electrophoresis was performed to identify presence of caseins and smaller peptides. For the second experiment, micellar casein slurries were prepared with a $25 \%$ protein content to simulate protein content in cheese. Samples were classified in two study groups, samples with chelators and rennet and samples with only chelators. Percentage of water soluble nitrogen analysis (\%WSN) was performed following Kjeldahl procedures to measure the break down of caseins into free soluble nitrogen and Urea-PAGE electrophoresis was used to measure the appearance of smaller peptides due to protein break down. Bands with a higher density on electrophoretic gels were an indication of a higher concentration of peptides due to possible increased exposure of caseins to proteolysis. For the second phase, samples with the 2 most significant chelator levels were selected to add a protease and measure with the same tests if there was a higher rate of proteolysis. The data showed no particular trend or significant difference between treatments $(p>0.05)$ for the $\% W S N$ test while some treatments showed a significant effect in samples treated for Urea-PAGE gels. In the Urea-PAGE analysis a different ANOVA was conducted on the percentage of alpha, beta, and gamma caseins for treatments before and after the incubation period separately and for the difference between both periods. These ANOVAs showed that the percentage difference in each casein before and after incubation was affected by the choice and level of chelator, and that these effects were modified by the presence or absence of rennet $(p<0.001)$. 


\section{ACKNOWLEDGMENTS}

Dr. Phillip S. Tong, Ph.D.

Professor of Dairy Science

Dr. John H. Walker, Ph.D.

Associate Professor of Statistics

Dr. Vincent Yeung, Ph.D.

Professor of Dairy Science

Dr. Rafael Jiménez Flores, Ph.D.

Professor of Dairy Science

Dr. Amy Marie Lammert, Ph.D.

Associate Professor of Food Science and Nutrition

Dr. Luis Fernando Castro, Ph.D.

Assistant Professor of Food Science and Nutrition

Vandna Sikand, Ph.D.

Research Scientist of Dairy Science

Matt Arnold

Research Associate of Dairy Science

Dairy Products Technology Center (DPTC)

California Polytechnic State University, San Luis Obispo 


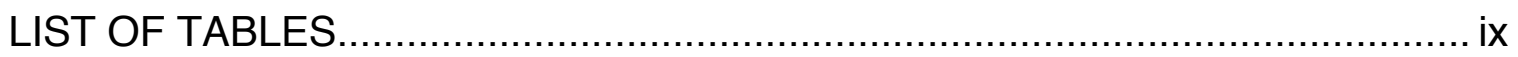

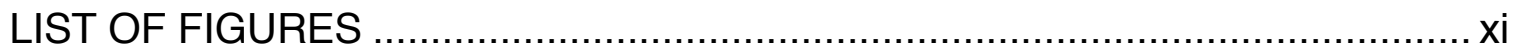

\section{CHAPTER}

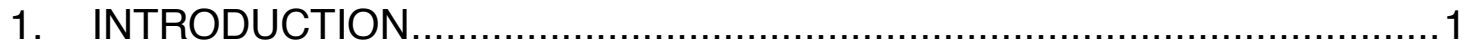

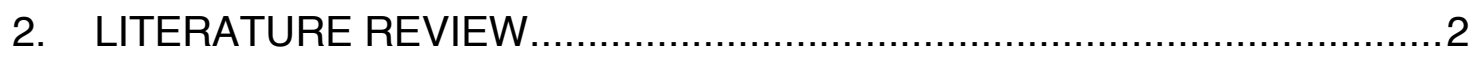

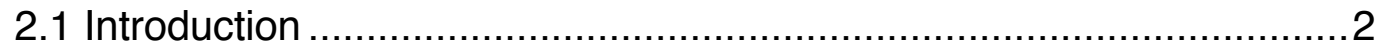

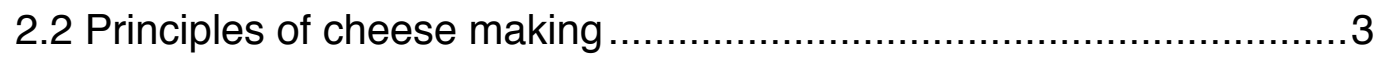

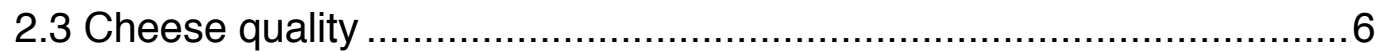

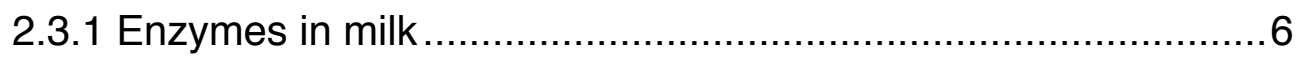

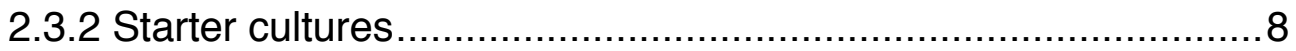

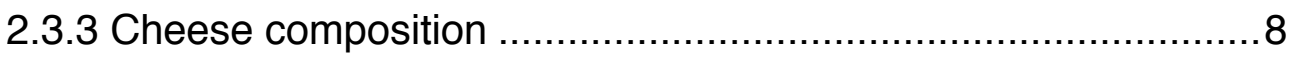

2.3.4 Ripening and storage conditions .......................................... 9

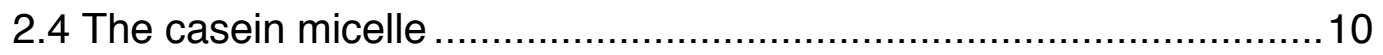

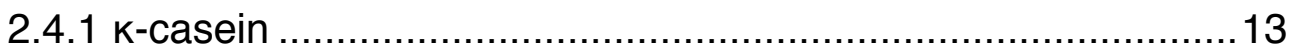

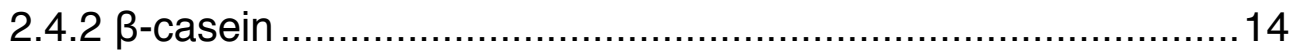

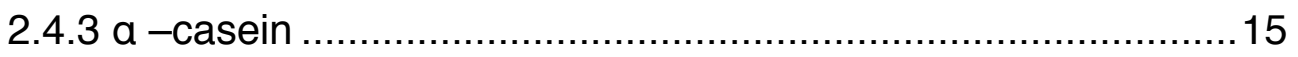

2.5 Rennet coagulation and chemistry............................................... 16

2.5.1 Proteolytic enzymes......................................................... 17

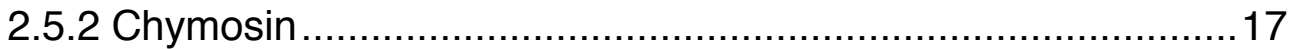

2.5.3 Coagulation and aggregation of micelles..............................19

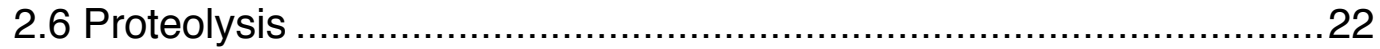

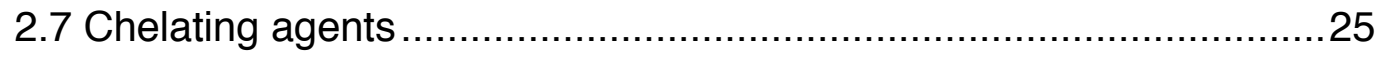

2.7.1 Definition and functional properties of chelators .....................25

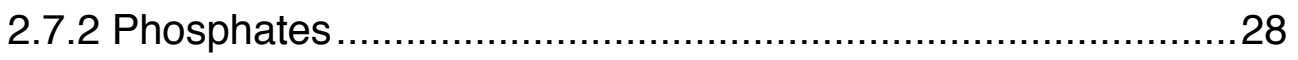

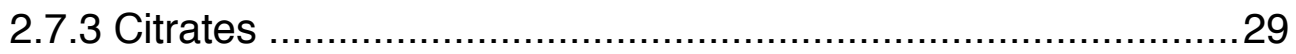

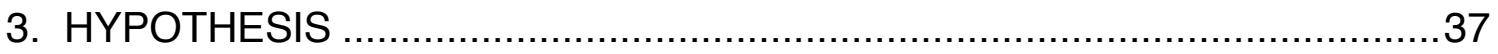

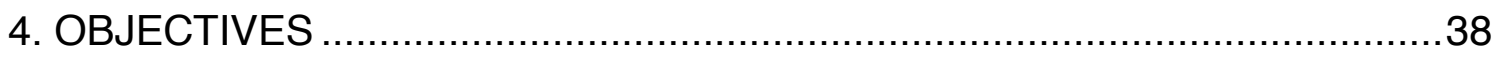

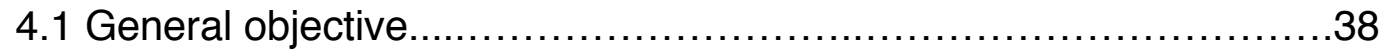




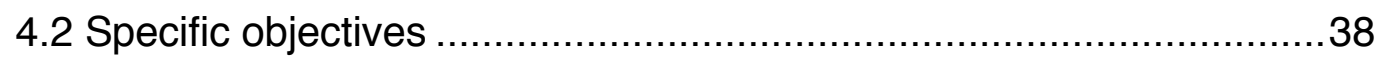

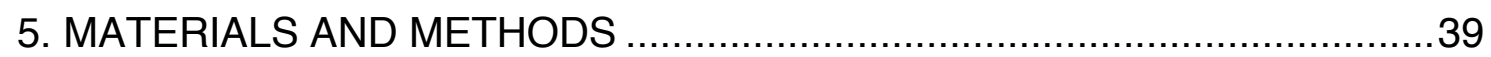

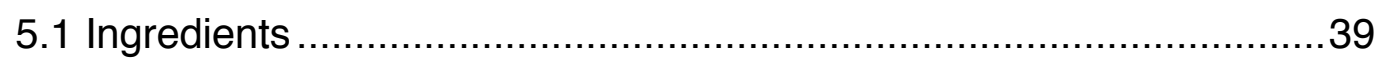

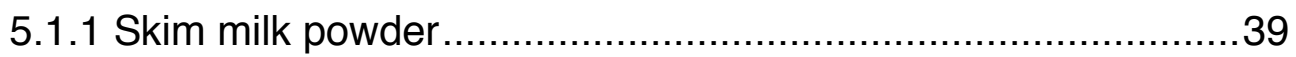

5.1.2 Coagulants and proteolytic enzymes ..................................39

5.1.3 Micellar casein powder ........................................................39

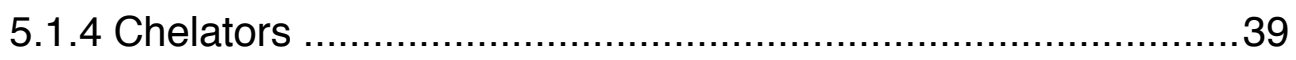

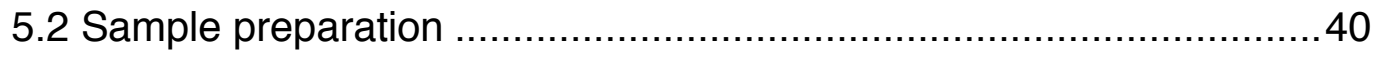

5.2.1 First experiment (preliminary trials) ...................................... 40

5.2.1.1 Reconstitution of milk powder ..................................... 40

5.2.1.2 Addition of chelators...................................................... 40

5.2.1.3 Addition of coagulant................................................... 41

5.3 Second Experiment ............................................................... 41

5.3.1 Preparation of micellar casein slurries ................................. 41

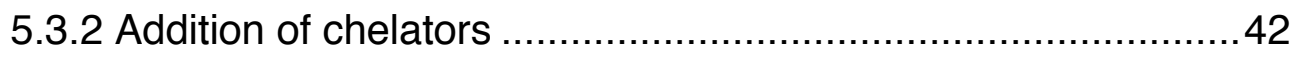

5.3.3 Addition of rennet/protease solution .................................... 42

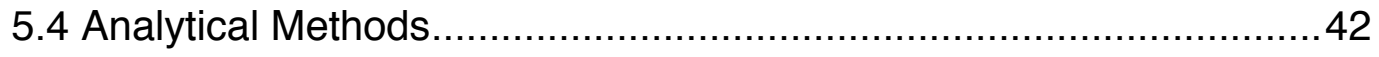

5.4.1 Preliminary coagulation studies (first experiment) ................ 42

5.4.2 Urea-PAGE electrophoresis................................................. 43

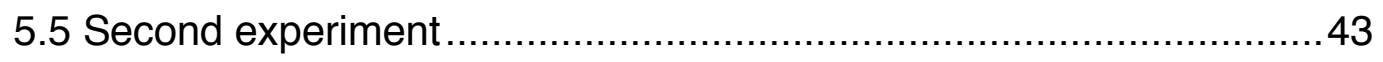

5.5.1 Extraction of water soluble nitrogen fractions ......................... 43

5.5.2 urea-PAGE electrophoresis ................................................ 44

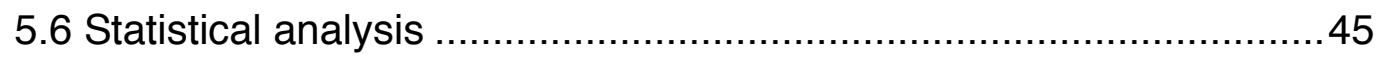

5.6.1 Water Soluble Nitrogen (\%WSN) .......................................... 45

5.6.2 Urea-PAGE electrophoresis............................................... 45

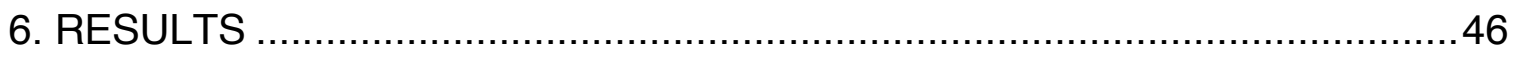

6.1 Preliminary coagulation studies (first experiment) .......................... 46

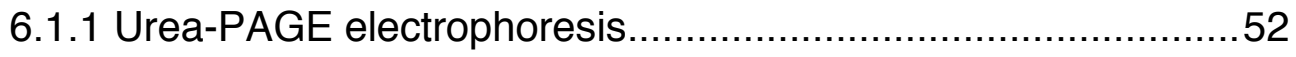

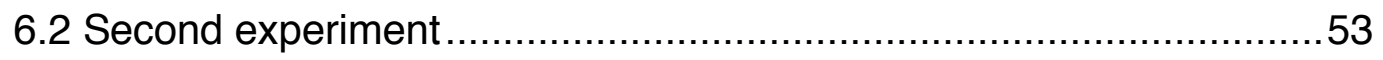

6.2.1 Water Soluble Nitrogen (\%WSN) ....................................... 53 


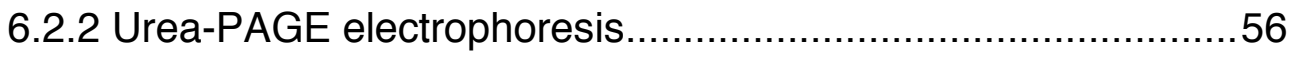

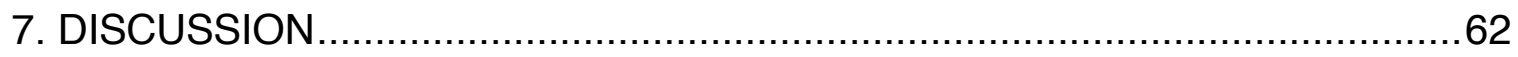

7.1 Preliminary coagulation studies (first experiment) .......................... 62

7.1.1 Urea-PAGE electrophoresis............................................... 63

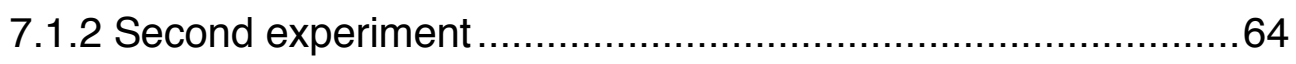

7.1.2.1 Water Soluble Nitrogen (\%WSN) ................................ 64

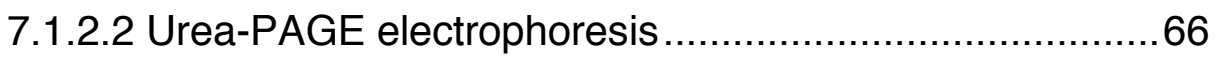

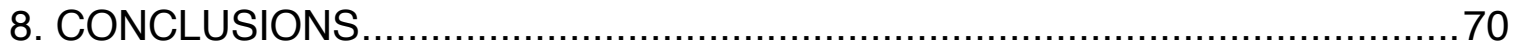

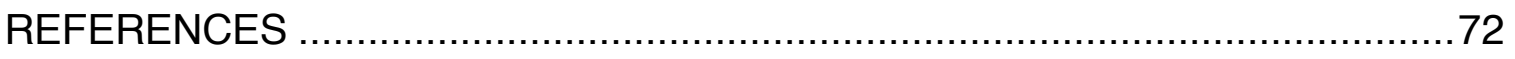

APPENDICES

A: Statistical analysis for \%WSN after incubation with control ......................78

B: Statistical analysis for \%WSN after incubation with log transformation ......79

C: Statistical analysis for Urea-PAGE gels before incubation for percentage

of gamma, beta and alpha caseins with controls......................................... 80

D: Statistical analysis for Urea-PAGE gels after incubation for percentage

of gamma, beta and alpha caseins with controls ....................................... 83

E: Statistical analysis for the percentage of gamma, beta and alpha caseins

in Urea-PAGE gels before incubation without controls ..................................86

F: Statistical analysis for the difference in percentage of gamma, beta

and alpha caseins in Urea-PAGE gels before and after incubation

without controls. 


\section{LIST OF TABLES}

Table

1. Coagulation time for fluid milk samples treated with NAHMP, SC

and rennet.

2. ANOVA table with log transforamtion for treatment effects after incubation period

3. ANOVA for the difference between treatments before and after incubation for gamma casein

4.Tukey's comparison for the effect of the interaction of chelator and enzyme level on the percentage of gamma casein

5. ANOVA for difference between treatments before and after incubation for beta casein

6. Tukey's comparison for the effect of the interaction of chelator and enzyme level on the percentage of beta casein

7. ANOVA for differences between treatments before and after incubation for

alpha caseins

8. Tukey's comparison for the effect of the interaction of chelator and enzyme level on the percentage of alpha casein

9. ANOVA table for $\%$ WSN before incubation with controls

10. ANOVA table for \%WSN after incubation with controls and log

transformation

11. ANOVA table for Urea-PAGE gels before incubation for percentage of gamma beta and alpha caseins with controls

12. ANOVA table for Urea-PAGE gels before incubation with controls for beta casein

13. ANOVA table for Urea-PAGE gels before incubation with controls for alpha casein

14. ANOVA table for Urea-PAGE gels after incubation for percentage of gamma beta and alpha caseins with controls 
15. ANOVA table for Urea-PAGE gels after incubation with controls for beta casein

16. ANOVA table for Urea-PAGE gels after incubation with controls for alpha casein

17. ANOVA for percentage of gamma casein before incubation without controls 86

18. ANOVA for percentages of beta casein before incubation without controls ..86 19. ANOVA for percentages of alpha casein before incubation without controls .86

20. ANOVA for the difference in percentage of gamma casein before and after incubation without controls

21. ANOVA for the difference in percentage of beta casein before and after incubation without controls.

22. ANOVA for the difference in percentage of alpha casein before and after incubation without controls 


\section{LIST OF FIGURES}

Figure

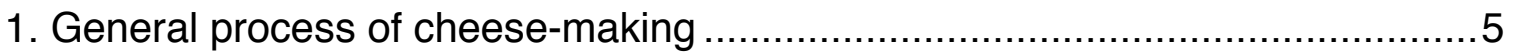

2. Model of a casein micelle proposed by Walstra (1990 and 1999) ................ 11

3. Structural model of a casein proposed by Schimdt (1982) ........................... 11

4. Structure of an individual micelle casein taken on a high-resolution field -emission scanning electron microscopy by Dalgleish, D. G., P. Spagnuolo

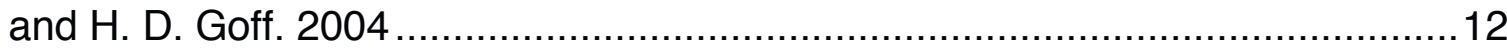

5. Association of CCP with serine phosphate groups of caseins

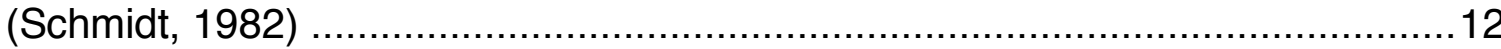

6. Primary and secondary phases of rennet coagulation (Swinscoe, 2013).......22

7. Reconstituted skim milk powder coagulated with rennet .............................47

8. Reconstituted skim milk powder coagulated with rennet .............................47

9. Example of the effect of SHMP on reconstituted skim milk powder. From left to right, skim milk with $2.5 \mathrm{mM}$, skim milk with $2.5 \mathrm{mM}$ and rennet, skim milk with $3.2 \mathrm{mM}$, skim milk with $3.2 \mathrm{mM}$ and rennet, skim milk with $10 \mathrm{mM}$, skim milk with $10 \mathrm{mM}$ and rennet

10. Effect of sodium citrate on reconstituted skim milk. From left to right: sample 1 skim milk with $5 \mathrm{mM}$, sample 2 skim milk with $15 \mathrm{mM}$ and sample 3 skim milk with $25 \mathrm{mM}$

11. Effect of sodium citrate on reconstituted skim milk powder at three different concentrations. From left to right the concentrations used were

$5,15,25 \mathrm{mM}$.

12. Effect of SHMP on reconstituted skim milk powder at 2.5, 3.2, 10mM. The order of concentrations is from left to right

13. Effect of SC on reconstituted skim milk powder at 5, 15,and $25 \mathrm{mM}$

(left to right).

14. Effect of SHMP at $2.5 \mathrm{mM}$ on reconstituted skim milk powder after centrifugation with rennet and no rennet added (left to right respectively) 50 
15. Effect of SHMP at $10 \mathrm{mM}$ on reconstituted skim milk powder after centrifugation with rennet and no rennet added (left to right respectively) ......... 50 16. Effect of $\mathrm{SC}$ at $5 \mathrm{mM}$ on reconstituted skim milk powder after centrifugation with rennet and no rennet added (left to right respectively).

17. Effect of $\mathrm{SC}$ at $25 \mathrm{mM}$ on reconstituted skim milk powder after centrifugation with rennet and no rennet added (left to right respectively) 51

18. Representative Urea-PAGE gel of reconstituted skim milk samples; lane 1 rennet milk (control); lanes 2-4 SHMP at 3 levels $(2.5,3.2,10 \mathrm{mM})$ and lanes 8-10 SC at 3 levels $(5,15,25 \mathrm{mM})$ 52

19. Representative Urea-PAGE gel of reconstituted skim milk samples treated with chelators and rennet; lanes 1-3 SHMP at 3 levels, lanes 4-6 TSPP at 3 levels; lanes 7-9 SC at 3 levels 53

20. Residuals vs predicted values of \%WSN after incubation period 55

21 . Residuals vs predicted values of $\% W S N$ after incubation period with log transformation

22. Representative Urea-PAGE gel of micellar casein slurry treated with SHMP (lanes 2 and 3) and SC (lanes 4 and 8) at two different concentrations, 2.5 and $10 \mathrm{mM}$; and 5 and $25 \mathrm{mM}$ respectively before incubation. Lane one is control. 56 23. Representative Urea-PAGE gel of micellar casein slurry treated with SHMP (lanes 3 and 5) and SC (lanes 7 and 9) at two different concentrations, 2.5 and $10 \mathrm{mM}$; and 5 and $25 \mathrm{mM}$ respectively before incubation with addition of proteolytic enzymes. Lane one is control 57 24. Representative Urea-PAGE gel of micellar casein slurry treated with SHMP (lanes 3 and 5) and SC (lanes 7 and 9) at two different concentrations, 2.5 and $10 \mathrm{mM}$; and 5 and $25 \mathrm{mM}$ respectively after incubation. Lane number one is the control 
25. Representative Urea-PAGE gel of micellar casein slurry treated with SHMP (lanes 3 and 5) and SC (lanes 7 and 9) at two different concentrations, 2.5 and $10 \mathrm{mM}$; and 5 and $25 \mathrm{mM}$ respectively and proteolytic enzymes after incubation. Lane one is the control

26. Representative lane plot of Urea-PAGE electrophoresis gels with image J. Higher peaks represent major caseins present in the system. Gamma, beta, and alpha from left to right respectively 


\section{Introduction}

Proteolysis is one of the most important biochemical events that happen during coagulation and ripening of cheese. It can be measured through several methods by quantifying different components that have a role in proteolysis such as rennet activity, rennet rate, and degradation of caseins, and release of glycomacropeptide.

Chelators are small molecules that bind very tightly to metal ions. In milk, calcium chelators shift the casein-mineral equilibria, leading to a decrease in concentration of free calcium ions, dissolution of CCP from the micelle, and release of specific caseins from the micelle (de Kort, 2012).

Calcium chelators, are commonly used in the dairy industry. Modification of the state of calcium by addition of chelating agents to milk followed by renneting, produces a non-coagulating milk.

We are interested in determining what effects chelating calcium has proteolysis of caseins. Finding novel ways to improve or accelerate proteolysis of proteins in milk if needed, could open the opportunity for new applications in the production of cheese flavors and slurries without prolonged aging periods which would represent better efficiency in time and cost. 


\section{Literature review}

\subsection{Introduction}

Cheese is one of the most diverse dairy products and has been thoroughly studied for the last few decades. It is a very active complex system that is subjected to biological, biochemical and chemical changes that result in different textures, flavors and functionality during storage. Cheese ripening is one of the most important steps in the process where the transformation of its major components (protein, fat and water) give the product its final characteristics. The proteins in milk called caseins constitute about $80 \%$ of the total composition of cheese and when subjected to rennet coagulation and proteolysis, they are responsible for the formation of the initial gel structure and development of flavor and aroma of what will eventually become a mature product. This thesis will begin by overviewing the principles and general steps of cheese making and will discuss the relevance of caseins. It will discuss how they are affected during proteolysis by enzymatic activity and the possibility of increasing their exposure and accelerating their rate of hydrolysis with external agents. These agents are known as chelators and are in charge of sequestering calcium which plays a key role during coagulation in the milk system. 


\subsection{Principles of cheese making}

In cheesemaking an enzyme preparation (rennet) is added to the milk. Rennet contains the enzyme chymosin, which cleaves off the glycomacropeptide (GMP) from the k-casein brush on the surface of the micelles. The micelles thereby lose their stability and flocculate in the presence of ionic calcium (De Kruif, 1999). All varieties of cheeses share a very similar protocol for their production but some steps can be altered to give the cheese a particular characteristic. The general process of cheese making consists of about six main steps each with specific operations explained bellow.

1. The manufacture of cheese begins with the selection of milk, where as it name indicates, milk is carefully selected to make sure its composition is appropriate for cheese manufacture and meets safety and quality specifications; then it is pretreated and standardized for many purposes. Depending on the variety, cheeses may have different fat, moisture, and protein content and these ratios can be modified by removing fat (creaming), or adding other ingredients such as skim milk, cream, milk powder, evaporated milk, ultrafiltration retentate or even calcium chloride to improve or promote coagulation.

2. The second step in the process involves adjusting and preparing the milk in order to make it suitable to initiate coagulation. Different ingredients are added to the milk such as the starter culture in charge of acidification, color if the cheese requires it, calcium chloride, and rennet, which is the enzyme responsible to initiate coagulation. 
3. When coagulation starts, it means that the milk acquires a gel structure, key to further formation of cheese as we know it. This coagulum is eventually cut, stirred and heated to separate the curds from the whey while the $\mathrm{pH}$ continues to decrease.

4. These fresh curds are subsequently subjected to more acidification and special operations depending on the cheese being made. Some of these operations can be cheddaring for cheddar, stretching for mozzarella and salting among others.

5. Molding and pressing of the curds follow these operations.

6. The fresh cheese goes into a period of ripening until it matures and is ready for consumption (Fox, 2000). 

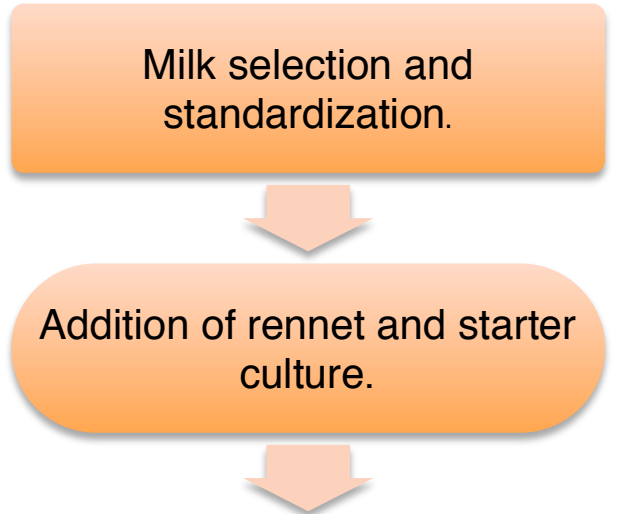

Coagulation of milk (gel formation). Cutting of curd and separation of whey

Acidification, cheddaring, stretching of curds.

\section{Molding and pressing of curds. \\ Storage and ripening of fresh cheese.}

Figure 1. General process of cheese-making. 


\subsection{Cheese quality}

\subsubsection{Enzymes in milk}

About 70 different indigenous enzymes have been identified in cow milk (Fox et al., 2003). With the exception of xanthine oxidase (XO), most of the indigenous enzymes in milk do not have relevant biological and physiological activity in the production of milk, and only very few function after milk secretion (Fox et al. 2006). The activity of microorganisms and enzymes from several different sources are responsible for the changes that occur during ripening and hence the quality of cheese. This variety of factors affect the composition of cheese and while many of them can be manipulated, others are almost impossible to control. The way the final product is affected starts very early on in the process with the milk supply; and microbiological, chemical and enzymatic aspects must be monitored.

Many of the enzymes in milk do not have the necessary substrates to metabolize and many of them remain inactive due to the conditions in the system, such as $\mathrm{pH}$ or redox potential. However, many indigenous milk enzymes are relevant for the following factors:

- Lipoprotein lipase (LPL) is responsible for deterioration and it is probably one of the most significant enzyme at a technological level in the dairy industry, along with proteinases, acid phosphatase and xanthine oxidase.

- Milk quality is affected by enzymes like lactoperoxidase (LPO), sulphydryl oxidase, and superoxide dismutase. 
- Temperature treatments can be monitored by the index of enzymes present in milk such as alkaline phosphatase, LPO, catalase, and $\gamma$ glutamyl transferase.

- Mastitis in cows accelerates the activity of $N$-acetyl- $\beta$-d-glucosaminidase, catalase and acid phosphatase.

- Lysozyme and LPO are main components of the LPO- $\mathrm{H}_{2} \mathrm{O}_{2}$-thiocyanate system used in cold pasteurization, and are related to antimicrobial activity (Fox et al., 2006).

Since the indigenous milk enzymes have no significant benefit in the nutritional or organoleptic properties of milk, it is common practice in the industry to destroy them with heat treatment (Fox et al., 2006).

As mentioned before, rennet is the primary coagulant added to milk during cheese manufacture. It contains the active enzyme, chymosin, responsible for gel formation and its main source is the calf's stomach but other microbial or vegetable sources are now available. The retention of rennet in the curd is affected by type, temperature and $\mathrm{pH}$ at draining. $\mathrm{A}$ higher retention of rennet results in a greater hydrolysis of alpha-casein, one of the main proteins in milk, which will be explained further on in section 2.4.

Milk is a very complex system that may contain up to 60 different indigenous enzymes. Some of these enzymes can potentially affect the quality of cheese. The most relevant enzymes to this process are lipase, proteinases, acid 
phosphatase, and some oxidases. Some of these enzymes may survive heat treatment during pasteurization and remain active during ripening.

\subsubsection{Starter cultures}

Starter cultures also play a significant role in the production and ripening of cheese. They produce acid, which decreases the $\mathrm{pH}$ of milk, and many of then release enzymes that contribute to the flavor, textural and aromatic characteristics of the final cheese product. These bacteria can produce sulfur compounds that contribute to the flavor of cheese varieties.

\subsubsection{Cheese composition}

Another very important factor that directly determines the quality of cheese is the chemical composition especially of fat, calcium, $\mathrm{pH}$ and caseins; and they particularly influence the coagulation phase and quality of the gel/curd structure. These constituents can be standardized in order to reduce their variability. The texture, flavor and shelf life of cheese is affected mainly by its moisture content, concentration of $\mathrm{NaCl}, \mathrm{pH}$, and the fat:protein ratio. These parameters have to be standardized and controlled so that young cheeses develop into good quality mature cheeses. 


\subsubsection{Ripening and storage conditions}

Cheese ripening can be a process that may last from a few days to several weeks or months and it is related to moisture. Cheeses with a low-moisture content ripen slower in comparison to cheeses with high moisture.

The sensory attributes of cheese form a very complex profile and are the result of the biochemical and chemical reactions that take place during the ripening process depending on the cheese variety. The initial quality of milk and the specific processing for each cheese variety result in a particular chemical composition of the cheese. Biochemical processes such as proteolysis, glycolysis and lipolysis are the main participants in the ripening of cheese (Collins et al., 2003; Delahunty and Drake, 2004; Fox and Cogan, 2004 and; McSweeney and Sousa, 2000). There are different methods implemented to accelerate ripening and they all have their advantages and disadvantages. Some practices include elevating the ripening temperature, adding exogenous enzymes, and addition of chemically or physically modified bacterial cells or starters, adjunct cultures, cheese slurries and enzyme-modified cheeses. These methods have disadvantages and limitations but they aim to accelerate ripening (Collins et al., 2003).

The general steps of cheese manufacture and the way its quality is affected have been discussed but there are other components that have an important relevance at a chemical structural level during the early stages of coagulation. Proteins in milk play a key role in curd and cheese production and are classified 
in four different types enclosed in a particular matrix call the casein micelle that will be discussed below.

\subsection{The casein micelle}

Caseins are a group of unique milk-specific acid-insoluble phosphoproteins and constitute about $80 \%$ of the total protein in the bovine milk and other commercial dairy species. Due to their commercial relevance, the caseins have been studied extensively and are one of the best-characterized food protein systems. Their relevance arises from the many physico-chemical properties of milk and dairy products, their structure and the effects of compositional and processing factors that have been studied quite extensively (Fox et al., 2008).

Caseins along with calcium phosphate, form the casein micelle, which is a spherical particle, dispersed in a continuous phase of water, salt, lactose and serum proteins. This system is very heat stable at $\mathrm{pH} 6.7$ and to many treatments such as boiling, addition of large quantities of salt or ethanol. They can be frozen an even dried; yet their properties are virtually unaltered. Compared to other colloidal systems, the micelle casein is one of the most stable ones (De Kruif, 1999). The casein micelle consists of the four different caseins $\left(a_{s 1^{-}}, a_{s 2-}, \beta-\right.$, and K-caseins) (Fox et al., 2008). Casein comprises 45-50\% a-s-casein, 25-35\% $\beta$ casein, 8-15\% k-casein, and 3-7\% $\curlyvee$-casein. $\alpha$-s-casein, $\beta$-casein, and $k$-casein are the main proteins that constitute the micelle but $\Upsilon$-casein is considered to be a $C$-terminal fragment of $\beta$-casein which is released by the activity of plasmin 
mainly befpre milk secretion from the cow's utter (Hurley, 2009). These proteins have an uneven distribution of polar and non-polar amino acid residues, which in addition to the hydrophobic and hydrophilic regions make the micelle very stable. Each casein fraction has different sensitivity to calcium, solubility, amino acid make up, and electrophoretic mobility.

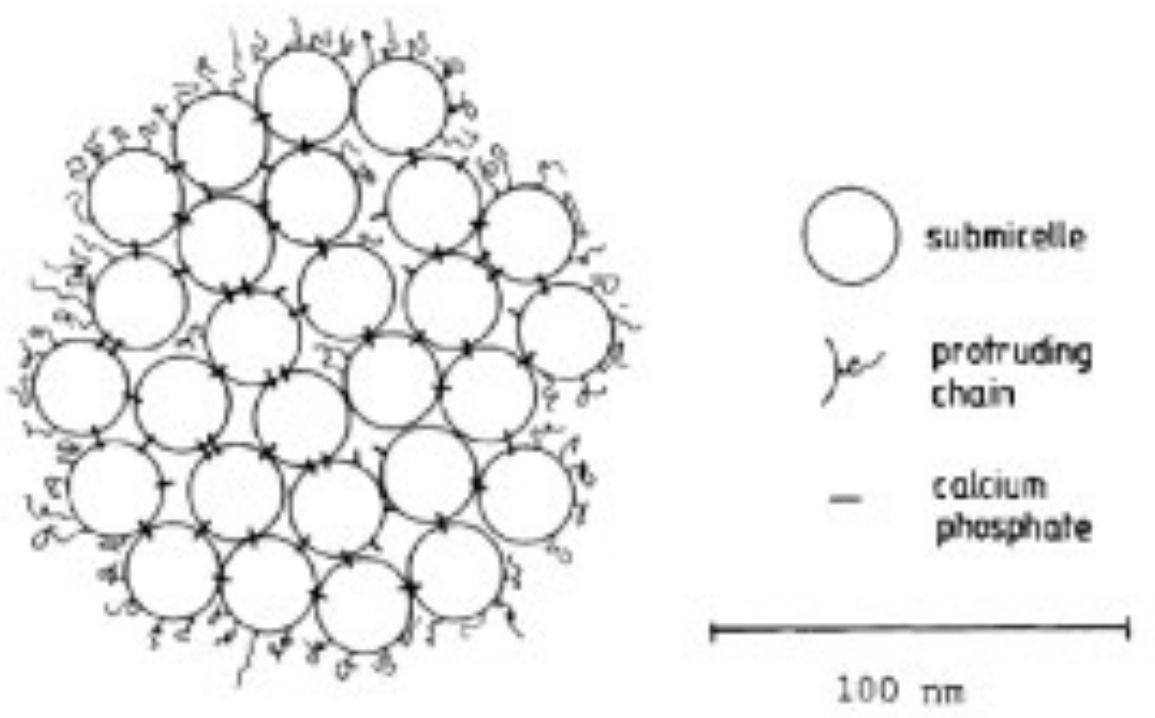

Figure 2. Model of a casein micelle proposed by Walstra (1990 and 1999).

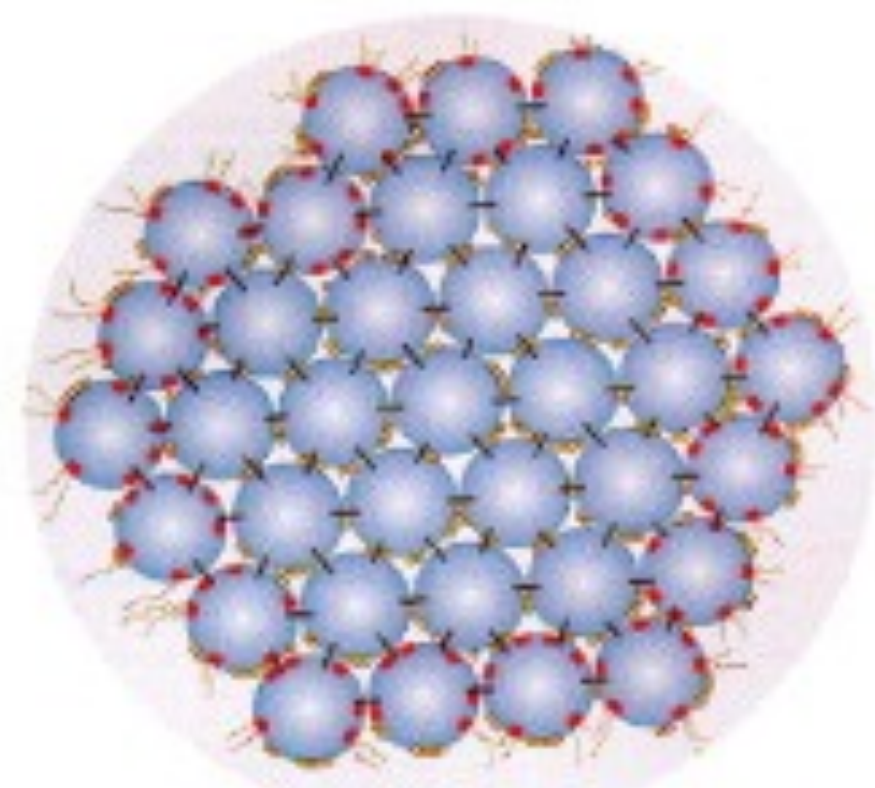

Figure 3. Structural model of a casein proposed by Schimdt (1982). 


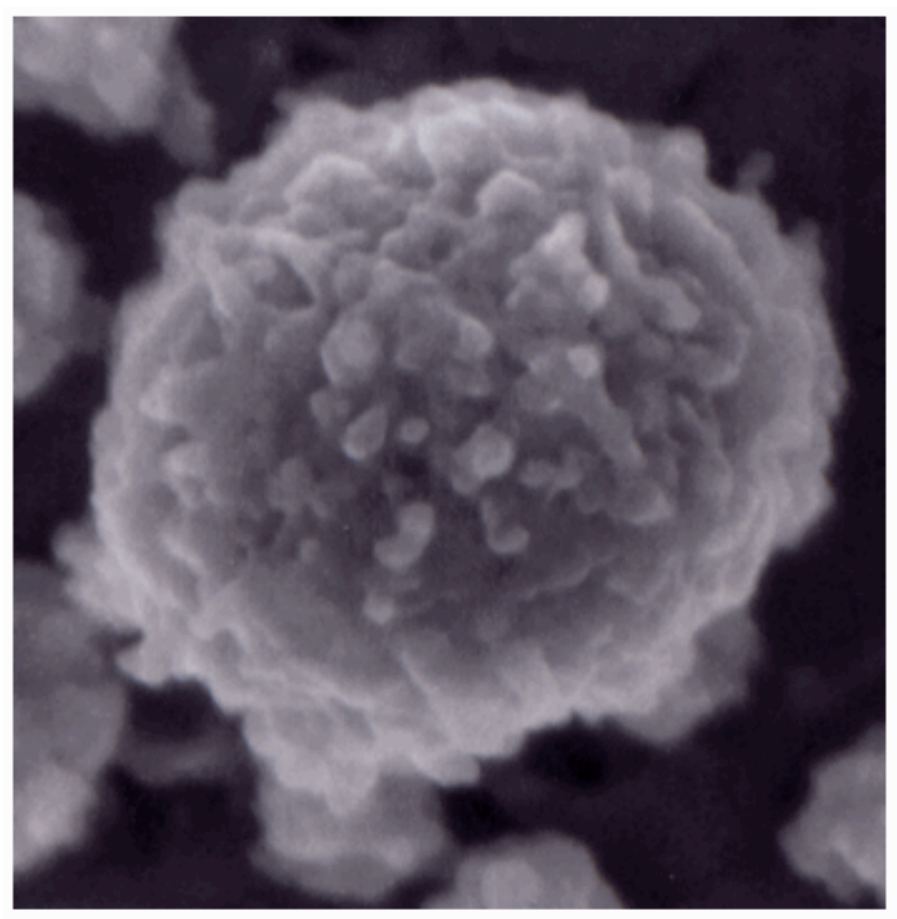

Figure 4. Structure of an individual micelle casein taken on a high-resolution field-emission scanning electron microscopy by Dalgleish, D. G., P. Spagnuolo and H. D. Goff. 2004.

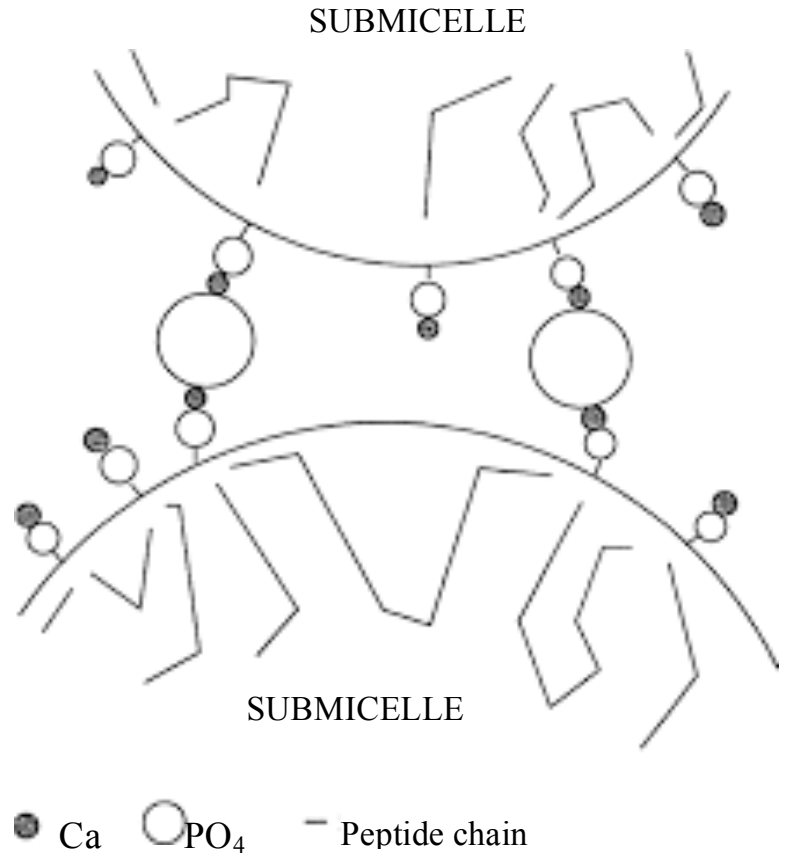

Figure 5. Association of CCP with serine phosphate groups of caseins (Schmidt, 1982). 


\subsubsection{K-casein}

The stability of casein micelles comes from the layer of the $\mathrm{k}$-casein brush on the surface of the micelles extending their C-terminal part into the soluble part of the milk system. This C-terminal region is extremely hydrophilic. k-Casein, which is soluble at the calcium concentration in milk and which is about $12 \%$ of total casein, can stabilize about 10 times its mass of Ca-sensitive caseins $\left(a_{\mathrm{s}^{-}}, a_{\mathrm{s}^{-}}\right.$ and $\beta$-) (Fox et al., 2008). It is negatively charged which means that it has the ability to repel other casein micelles and causes milk to stay in a liquid form. $\mathrm{k}$ Casein also provides stability and protection to the calcium sensitive and hydrophobic interior of the micelle where $\alpha$ and $\beta$ caseins are located. These caseins have phosphoserine residues and high calcium affinity. $\mathrm{k}$-casein has few phosphoserine residues and a carbohydrate called $\mathrm{N}$-acetyl neuramic acid, which makes it hydrophilic and resistant to ionic calcium (Fox et al., 2004). This suggests that, if that brush was not dense enough or the molecules were too rigid, or collapsed on the surface, there would be no stabilization, and they would consequently flocculate and gel (De Kruif, 1999). It was shown that K-casein is the micelle stabilizing protein and that its stabilizing properties are destroyed on renneting. In addition, it is the only protein that undergoes hydrolysis during the rennet coagulation of milk (F. Fox et al., 2000). When chymosin cleaves k-casen, it cuts the negatively charged end of its chain separating from the rest of the micelle and dissolving into the liquid phase. Eventually this end will separate along with the whey. If the casein micelles are given an enzymatic treatment or 
acid rinse, the k-casein brush will be cleaved and form a weak gel and eventually aggregate. Thus, by considering the micelles as a group of particles clustered together and stabilized by a brush of $\mathrm{K}$-casein, it is possible to begin to understand the way they react to technological treatments by observing the behavior of the K-casein brush (De Kruif, 1999).

\subsection{2 $\beta$-casein}

Bovine milk contains about $80 \%$ casein of which $35 \%$ is $\beta$-casein $(\beta-C N)$ (Fox, 1992) and is located in the interior of the micelle along with alpha casein protected by the layer of kappa and bind to them through colloidal calcium and serine phosphate groups forming bridges. Up to $50 \%$ of $\beta$-casein, the most hydrophobic of the caseins, dissociates reversibly from the micelles on cooling, indicating the importance of hydrophobic interactions and suggesting that the micelle is sufficiently porous to allow the $\beta$-casein to diffuse out of the micelle; on rewarming, the $\beta$-casein appears to form a fuzzy layer on the surface (Fox et al., 2008). $\beta$-casein possesses both a short $\mathrm{N}$-terminal hydrophilic polar domain and a large C-terminal hydrophobic domain (Xuefeng et al., 2004).

$\beta$-caseins have been studied and it was shown that it has noticeable antiaggregation properties (Xuefeng et al., 2004); Morgan et al., 2005). A considerable chaperone-like activity was demonstrated for bovine $\beta$-casein. Molecular chaperones are a family of proteins that are believed to have evolved for preventing protein aggregation under unfavorable conditions by blocking the 
hydrophobic surfaces exposed from the denaturing substrate proteins. The betacasein, a protein with high heat stability (Swaisgood, 1993), is one of the commonly used substrate proteins for analyzing proteolysis activities in vitro (Faccio et al., 2000; Hu et al., 1998; Lipinska, Zylicz, \& Georgopoulos, 1990) and it is more resistant to hydrolysis and aggregation than alpha casein. Hence its relevance during rennet coagulation and proteolysis in cheese making.

\subsection{3 a -casein}

In bovine milk, $65 \%$ of the casein fraction is comprised of the $\mathrm{a}_{\mathrm{S} 1}-$ and $\mathrm{a}_{\mathrm{S} 2}$ subunits (known collectively as a -casein) (Bhattacharyya et al., 1999). S1 is the $\mathrm{S}$

dominant $a_{s}$ subunit. Along with beta caseins, alpha caseins are calcium sensitive and precipitate to different degree in presence of the latter. They are also related to transport of calcium and other metal ions to neonates. This casein

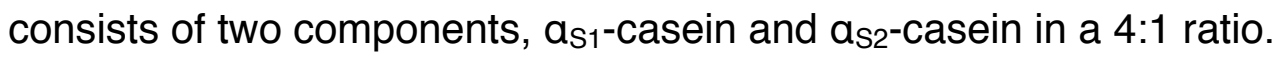

Bhattacharyya et al. (1999) discuss that $a_{s}$-casein, is found abundantly in mammalian milk; it has no well-defined secondary and tertiary structures but it happens to exist in nature as a micellar aggregate. a -casein can prevent a $s$

variety of unrelated proteins/enzymes against a range of different types of aggregation from thermal, chemical to light induced. It can also prevent aggregation of the whey proteins. $a_{s}$-Casein interacts with partially unfolded proteins through its hydrophobic end. The absence of disulfide-bridge or free thiol 
groups in its sequence plays important role in preventing thermal aggregation of whey proteins. Their results indicate that $a_{s}$-casein not only prevents the formation of huge insoluble aggregates but it can also inhibit accumulation of soluble aggregates.

\subsection{Rennet coagulation and chemistry}

Coagulation of milk is a crucial step in cheese production because caseins (milk proteins) are destabilized as an initial step to separate whey proteins from caseins and initiate curd formation. Gelation can be induced by rennet (chymosin enzyme) action, acidification or combination of acid and rennet (Lucey, Johnson, \& Horne, 2003). During rennet-induced coagulation, proteolytic enzymes are added to the milk to induce proteolysis and hydrolyze the N-terminal part of $\mathrm{K}$ caseins into para-k-caseins and glycomacropeptides reducing electrostatic repulsion and stability of the micelle. Rennet coagulation happens in two stages that involve cleavage and aggregation of caseins, which will be explained in section 2.5.3. 


\subsubsection{Proteolytic enzymes}

Proteolytic enzymes can be classified depending on their catalytic activity. There are four groups -serine, cysteine, metallo, and aspartic proteinases (Kay,1985). Chymosin is a neonatal gastric aspartic proteinase. This family of enzymes is widely distributed in many organisms and tissues with many physiological and functional properties (Chitpinityol and Crabbe,1998). They can be found in a variety of organisms from viruses to higher plants and animals and are frequently classified into two major groups - pepsin-like and retroviral enzymes. These peptidases have been isolated from major sources such as the stomach, lysosomes of cells, tissues like kidney and glands, plants, and microorganisms. The active site of aspartic proteinases is highly conserved and contains three residues, Asp-Thr-Gly, in each domain of the enzyme. Peptidases are in charge of hydrolyzing large proteins and converting them into smaller peptides until they eventually become individual amino acids which are intimately related to flavor and aroma characteristics in dairy products.

\subsubsection{Chymosin}

As mentioned before the first stage of coagulation happens due to the action of rennet (chymosin). The function of chymosin in the stomach of calves is to coagulate the milk they drink and it is considered to be a functional enzyme that is effectively adapted to the process of cheesemaking (Ye et al., 2000). 
When comparing chymosin with the structure of other aspartic proteinases, a high degree of structural homology is observed. This means that even if these proteinases come from different sources, there are structural similarities. Chymosin is the most similar out of all these enzymes to porcine pepsin and to some fungal proteinases.

The active site of chymosin affects k-caseins and cleaves the phenylalaninemethionine bond (105-106) of these caseins, which eliminates its stabilizing property among alpha and beta caseins.

Chymosin produces a smooth curd and it can resist small changes in $\mathrm{pH}$ that may occur in milk due to natural variation. This enzyme is widely used because it does not cause bitterness in the milk and does not have proteolytical activity if the cheese is a supplement in other foods. Chymosin will perform in milk at $\mathrm{pH}$ 6.0-6.4 and at $20-30^{\circ} \mathrm{C}$, although its optimal $\mathrm{pH}$ is approximately 4. Coagulation happens best at $40^{\circ} \mathrm{C}$, but milk for cheese making is coagulated at $31-32^{\circ} \mathrm{C}$ because at this temperature the curd has rheological characteristics suitable to make cheese. If the $\mathrm{pH}$ is higher than 7 , then the activity of the enzyme will be lost. Chymosin is a very sensitive enzyme to different practices such a shaking, temperature, alkali, dilutions and other chemicals. It is most stable when stored at $7^{\circ} \mathrm{C}$ and $\mathrm{pH}$ at 5.4-6.0 in darkness. Liquid and powder rennets are different and may be used in different processes. Chymosin that comes from bovines is more specific for cow's milk than chymosin that comes from other animals such as goats. 
Milk contains protein, salts, fat, sugar and other minor components such as vitamins and minerals in solution, emulsion or suspension. When milk is converted into cheese, these components are concentrated in the cheese, but others get lost in the whey. In rennet coagulation and the removal of whey, the separation of these components occurs selectively, and in the resulting curd, many agents of biological importance get activated, marking the development of the final product.

\subsubsection{Coagulation and aggregation of micelles}

Once the coagulating enzymes are added, this type of coagulation is developed in two phases but cannot be visually distinguished. Only when a curd appears, both steps are completed:

Phase one: The first stage involves the modification of the casein micelles by enzymes to produce para-caseins that will eventually aggregate in the presence of $\mathrm{Ca}^{+2}$ (F. Fox et al., 2000) and the $\mathrm{N}$-terminal part of the protein (para-kcaseins) remains attached to the micelle, whereas the C-terminal (macroglycopetide) detaches into the liquid medium (De Kruif, 1999). There are many factors that influence the hydrolysis of k-caseins and have an effect on the formation of the gel, and this directly affects the characteristics of the final cheese product. Interactions within and between caseins are not only strongly influenced by the concentration, size and internal strength of the micelles, but also by their

environment. Some of these parameters that determine these interactions are: 
chymosin concentration, $\mathrm{pH}$, calcium concentration, ionic strength, temperature, heat treatment, and milk processing. Once k-caseins are hydrolyzed and transformed into para-k-caseins, the charges of the micelle are neutralized which initiates the second phase.

Phase two: After the first phase of rennet coagulation occurs, aggregation takes place. When about $85 \%$ of the total $\mathrm{k}$-caseins has been hydrolyzed, the micelles become very unstable to the point of aggregation, and they remain this way until they form a three-dimensional network known as coagulum or gel. This happens because the hydrolyzed K-casein chain is now sensitive to binding to minerals and it links with phosphate and calcium to form bridges that bring all the micelles together and form a gel. This gel increases its viscosity and a property called elastic shear modulus, which is a measure of gel firmness. Increasing or reducing factors such as $\mathrm{pH}$ and temperature from their normal values promotes coagulation at a lower level of hydrolysis. However the exact reactions that participate in aggregation are not known. The gelation process (secondary phase) involves the formation of clusters of micelles and leads to the formation of a network of micelles. At first, the micelles exist as individual particles; once $85 \%$ of the enzymatic reaction has occurred, the rennet-altered micelles begin to aggregate in small chains and then form the network. Initially, most micelles are joined by bridges and do not touch. In this second nonenzymatic phase of coagulation, other factors may affect renneting significantly. The coagulation of 
micelles in bovine milk depends greatly on temperature and they will not coagulate at less than around $18^{\circ} \mathrm{C}$ unless there is a high concentration of $\mathrm{Ca}^{2+}$.

This very high temperature dependence suggests that hydrophobic interactions are very important. Likewise, a critical concentration of $\mathrm{Ca}^{2+}$ as well as colloidal calcium is needed; interaction with various cationic species predisposes the micelles to aggregate by rennet and may coagulate unrenneted micelles. Micellar charge is important in the coagulation of rennet-altered micelles and it suggests that $\mathrm{pH}$ may have a bigger effect on the secondary stage of aggregation. By reducing the $\mathrm{pH}$ to $6.6-6.0$, the rate of the enzymatic and coagulation reactions increases while gelation time and the degree of $\mathrm{k}$-casein hydrolysis needed for gelation decrease from about $97 \%$ to $80 \%$. The curdfirming rate and the firmness of the gel are also influenced by $\mathrm{pH}$. Milk may undergo conditions during heat treatment that denature $\beta$-lactoglobulin and promotes the interaction with caseins, which affects the way the gel network forms. It is suggested that the attachment of denatured $\beta$-lactoglobulin to the surface of the micelle prevents aggregation and the formation of a coagulum.

The rennet gelation of milk involves its conversion from a colloidal dispersion of micelles into a network of aggregated paracasein micelles, which is a continuous phase that holds fat and moisture. Overtime, many changes happen, this network becomes more viscous, elastic, and firm; and the concentration of glycomacropeptide increases (F. Fox et al., 2000). 


\section{Primary Phase}
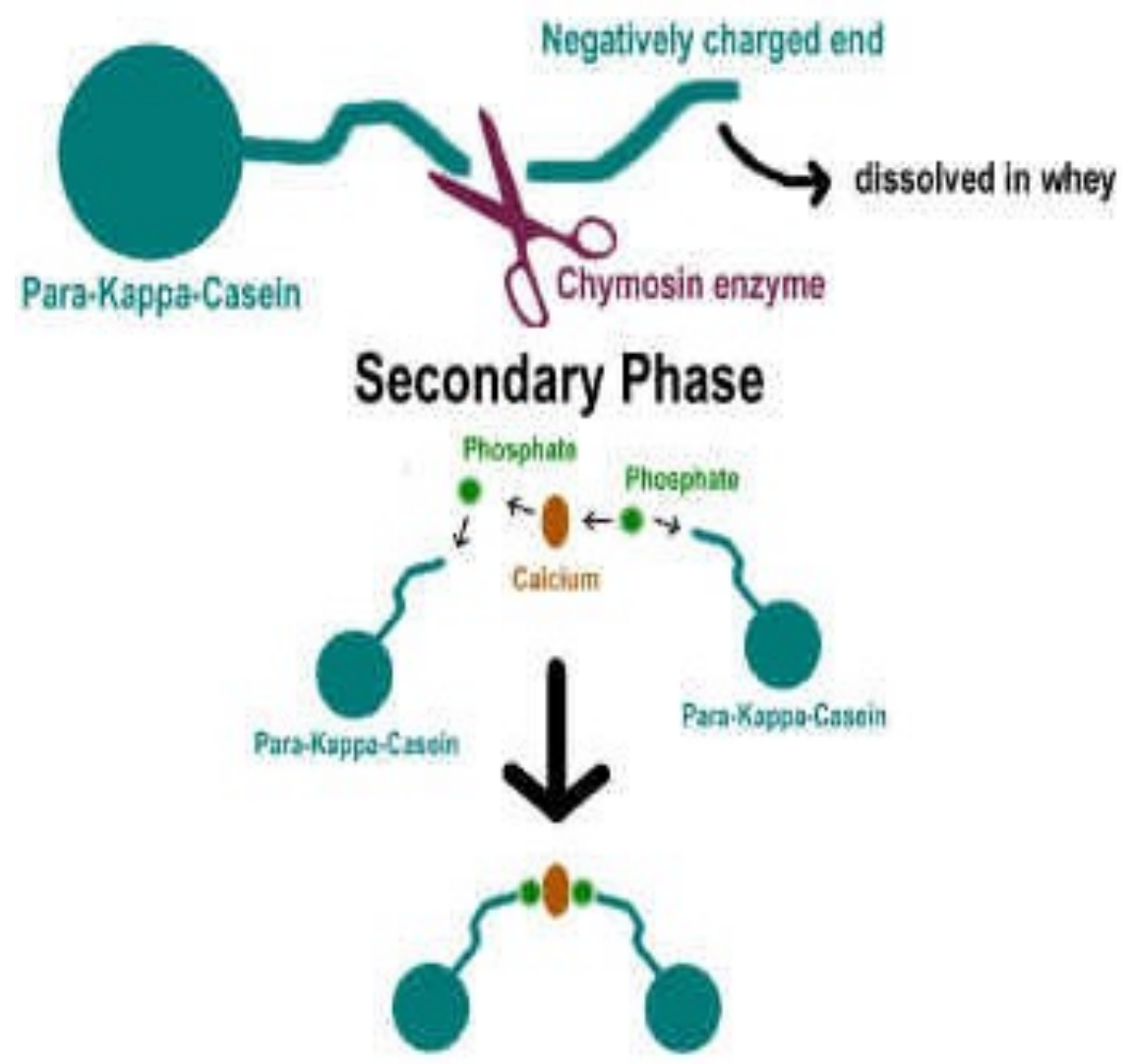

Figure 6. Primary and secondary phases of rennet coagulation (Swinscoe, 2013).

\subsection{Proteolysis}

Proteolysis is one of the most complex and important biochemical events that happen during coagulation and ripening of cheese and it has a direct effect on the flavor and texture of the product. Proteolysis is an essential step during maturation in almost all varieties of cheese and its duration, can vary in the size from polypeptides that are produced only smaller than the intact caseins to free amino acids (Fox, 2000). This biochemical phenomenon is constantly monitored 
and is a very good indicator of the quality and maturity of cheese. It can be measured through several methods by quantifying different components that have a role in proteolysis. These methods are classified into two groups, specific and nonspecific. The latter can determine the degradation of caseins soluble nitrogen in different solvents or precipitants and quantified by methods such as Kjeldahl, Biuret, Lowry, among others. The relevance of these methods lays on their ability to estimate the overall extent of proteolysis and the contribution of the proteolytic agents involved. Nonspecific methods are useful because of their simplicity. They can be implemented to perform routine assessments of cheese maturity since soluble nitrogen is a good indicator of the age and in some way the quality of cheese (Fox, 2000). It has been discussed by some authors that proteolysis may happen in milk before coagulation or during ripening of the cheese. Fox (1989) divided proteolysis in three different phases to study and understand what happened during each step of the process in cheese making. $\mathrm{He}$ measured proteolysis in pre-manufacture, coagulation and ripening. $\mathrm{He}$ explains that there are two main factors that trigger proteolysis in premanufacture: microorganisms and indigenous proteinases; the most important is plasmin which hydrolyzes $\beta$-casein. Destabilization of caseins and formation of the gel, as mentioned before, occurs during coagulation, and during ripening many chemical and biochemical changes take place and the principal constituents of cheese such as proteins, lipids, and residual lactose are degraded to primary and secondary products. The main compounds that have been 
identified in several cheeses are peptides, amino acids, amines, acids, thiols, thioesters derived from proteins and other products derived from lipids and lactose. In the right balance, these compounds are responsible for the unique flavor and aroma of different cheeses. Proteolysis is responsible for ripening in more than four ways. One of them is the direct contribution to flavor via amino acids and peptides; another one is the release of sapid compounds during mastication, and changes in $\mathrm{pH}$ and in texture by breaking down the protein network. In some varieties such as Romano or Parmesan, lipolysis is primarily responsible for their characteristics. However, proteolysis is important in all cheeses, in some cases more than others. Cheeses like cheddar are considered to develop due to the major biochemical event happening during ripening. Thus, proteolysis is studied and considered as one of many indices of cheese maturity. Proteolysis in cheese is a widely researched topic and there is a considerable amount of information available about the rate and type of proteolysis.

During coagulation only about $6 \%$ of the rennet is retained in the gel network, and the proportion of chymosin retained increases as the $\mathrm{pH}$ decreases during separation of whey (Fox, 1989). The specificity of chymosin on individual casein is well known, as well as the effect of $\mathrm{pH}$. Both $\mathrm{a}$ and $\beta$-caseins have susceptible bonds to chymosin but only a few undergo hydrolysis in cheese. In all varieties of cheeses, $a_{s 1}$-casein is the main target for proteolysis in cheese made using commercial rennets. 
Rennet acts differently depending on the casein it is hydrolyzing. $\beta$-casein bonds are not hydrolyzed by rennet in cheese, possibly due to hydrophobic interactions between the $\mathrm{C}$-terminal parts of $\beta$-caseins. These $\mathrm{C}$-terminal regions

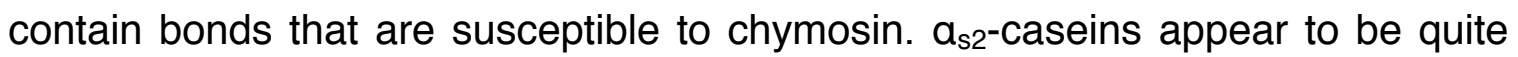
resistant to hydrolysis in cheese, as well as para-k-caseins; and even though $\mathrm{Y}^{-}$ caseins contain the bonds of $\beta$-caseins that are susceptible to chymosin, they accumulate during ripening. One reason could be that these bonds in $\gamma$-caseins are inaccessible (Fox, 1989).

\subsection{Chelating agents}

\subsubsection{Definition and functional properties of chelators}

A chelate is a compound that results from combining a metal ion and a molecule called ligand that has the ability to form two or more bonds with the metal. These bonds result in a ring structure that includes the metal ion.

Chelates are very important in foods and biological systems and widely used in the food industry. They are normally added to foods to sequester minerals such as iron, copper and calcium. They have a significant role in foods because they stabilize them through chemical reactions with metallic and alkaline ions. This ions change their properties as soon as they come together and therefore the properties of foods. Many of these agents used in foods can be naturally found as acids and macromolecules and many metals are already naturally chelated in enzymes, proteins and other compounds in blood. When these ions 
are released into the food system, they react and initiate degradation processes such as discoloration, oxidative rancidity, turbidity and change in flavor. Chelators are added in many cases to make those foods more stable and prevent or slow down these degradation reactions. Any molecule that has an unshared pair of electrons can bind with metal ions and form compounds. Citric acid and its derivatives, many phosphates and EDTA salts are mainly used in foods (Fennema, 1996). In milk systems, chelators shift protein-mineral equilibria, which leads to a decrease in the concentration of free calcium ions, depletion of CCP, and the release of very specific caseins from the micelle. It has been studied that these shifts increase the repulsion between the negative charges of the amino acids in the micelles which results in and increased hydration and voluminosity of the micelle. These micelles eventually dissociate into small clusters of caseins and dispersed proteins as the level of chelators in the system rises. Panouillé et al. (2004) and Pitowski et al. (2008) demonstrated that both intact and dissociated caseins could be present simultaneously in the milk solution after adding chelators. The extent to which chelating agents affect the structure of the micelles depends on their concentration and calcium- binding capacity and the way they interact with the calcium ions and amino acids in the micelle. In addition to the generic properties of calcium-binding, chelating agents may generate specific effects (De Kort, 2012).

The dairy industry uses many different calcium-binding agents such as citrate, polyphosphates, or pyrophosphates, and they are known by the name of 
chelators (Gaucheron et al., 2005; Vujicic et al., 1968). These chelators influence the activity of calcium in solution, the CCP concentration, and thus the heat stability of casein micelles in dairy systems (Gaucheron et al., 2005).

Micelle formation is determined by a combination of hydrophobic interactions and electrostatic repulsion with colloidal calcium phosphate which relevance relies on its binding properties between caseins. It has been studied that the $\mathrm{Ca}$ and phosphate distribution between the two different phases (soluble and insoluble) has a direct impact on the functional properties of cheese (Lucey et al., 2003; Hassen et al., 2004; O'Mahony et al., 2005). The amount of colloidal calcium phosphate can be modified by different methods like heating and cooling or by the addition of chelating agents (Udabage et al., 2000). The most common salts used in the dairy industry are phosphates and they have the property of binding and sequestering metal ions, which leads to a shift in a protein-mineral equilibrium where the calcium dissociates from the casein micelle resulting in a weak or non-existing gel. Salts of phosphoric, citric and tartaric acid are also known as emulsifying salts in the industry of processed cheese (JOHA, 1989).

Sodium salts from phosphoric or citric acids are used to among other things, alter and decrease the susceptibility of dairy products to gelation. Thus, calciumchelating salts are widely used to manufacture processed cheese. Different milk systems have been studied to understand the effects of these chelating salts on the properties of casein micelles. De Kort (2012) studied the effect that these calcium chelators have on the physical changes of casein micelles in 
concentrated micellar casein systems by measuring viscosity, calcium-ion activity, turbidity, and performing ultracentrifugation. The complexity of the nature of these interactions lies in the fact that it is very difficult to set apart the effects of calcium chelation and the associated shift in $\mathrm{pH}$ due to the addition of these salts. $\mathrm{pH}$ is one of the main factors that affect the properties of casein micelles, thus, it needs to be kept constant. Another difficulty is that these chelating agents are commonly used as mixtures in commercial practice, and it is not simple to separate the effect of individual chelating salts (Kaliappan et al., 2011).

\subsubsection{Phosphates}

Phosphates are salts that come from phosphoric acid and within this type of salts there are subcategories or subdivision depending on the length of the chain. Short-chained phosphates can be di- or triphosphates and are also known as pyrophosphates. The group of long chained phosphates are glassy salts and consist of different chain lengths. An example of these phosphates is sodium hexametaphosphate (SHMP) which is an inorganic phosphate commonly used in dairy products to influence and improve the quality of products like evaporated milk, processed cheese, or calcium-enriched milk (Vujicic et al., 1968). This kind of chelator binds to calcium and charges the amino acids in the casein residues positively which gives it a particular ability to cross-link casein micelles and form a gel structure in the milk system (De Kort, 2012). De Kort (2012) hypothesized that this is possibly due to the form and distribution of the charges around the molecules of protein. SHMP has six negative charges distributed in a 
homogenous way around the molecule and this allows the chelator to interact with cations and caseins simultaneously. SHMP also has an effect on the amount of CCP present in the casein micelle by binding to calcium ions (Mizuno et al., 2005; Odagari et al., 1964; Odagari et al., 1964; Odagari et al., 1965). SHMP is a potent chelator and the way it binds to cations is equal for the different minerals in the system like calcium, magnesium, strontium, and barium. The extent of interaction of polyphosphates is, in general, dependent on the chain length of the polyphosphate (Udabage et al., 2000).

Phosphates have a great binding capacity for cations. They behave as soluble and can exchange ions as well as mask and inactivate cations. They also have an effect on colloidal-chemical bonds such as colloidal calcium phosphate in milk and are able to break down peptides, disperse hydrate proteins, and stabilize emulsions. The effect of phosphates and citrate on the changes of milk solutions has been studied in skim milk systems where the amount of whey protein is about $20 \%$ and using low levels of chelators (De Kort, 2012).

\subsubsection{Citrates}

Citrates are salts of citric acid, which is dissociated and can form hydrogen and hydrogen citrates. They can be mono-, di- or tri-sodium citrates. The latter is commonly used as an emulsifying salt. In the industry, the salts of more interest are sodium citrate and tri-sodium citrate dehydrate for its applications and storage properties (JOHA, 1989). 
Shalabi and Fox (1982) discovered that renneted milk did not coagulate when the content of colloidal calcium phosphate was altered and decreased by approximately $30 \%$ at constant calcium activity. The addition of chelating agents affects the activity of free calcium, CCP, the proportion of caseins in the micelle and the ionic strength of the milk system. The calcium-ion activity decreases with the addition of phosphates and citrates because these ions are chelated from the micelles and the serum phase (De Kort, 2012).

Citrates and phosphates are commonly used as emulsifying salts in cheese making. They are not considered true emulsifiers but they increase the dispersion of caseins, the water-holding capacity of proteins and the ability of caseins to act as emulsifiers of fat. However, the way chelating agents interact with the cheese system is not fully understood. Mizuno and Lucey (2005) studied a simpler system to understand the activity of chelating agents on caseins. Instead of analyzing a more complex system such as cheese, they used a milk protein concentrate to provide information about the chemical behaviors of chelating agents when they are used in cheese manufacture. Samples were treated with tetrasodium pyrophosphate (TSPP), trisodium citrate (TSC) and sodium hexametaphosphate (SHMP) their results showed that phosphate anions from TSPP and SHMP combined with caseins and Ca formed a new type of insoluble calcium phosphate. SHMP is commonly used in processed cheese, but the changes that it causes in the interactions between phosphates, caseins and indigenous calcium is not very well understood. The action of chelating agents 
results in the disruption of the interaction between caseins that attracts them to one another, causing the casein matrix to disperse. There is also the formation of compounds formed between the chelating salts and the calcium that promote the cross linkage of casein micelles in the gel. Chelating agents differ in their capacity to bind to calcium and to disperse or crosslink casein micelles. Another factor that affects the number and type of attractive interactions is the concentration of the chelators (Shirashoji et al, 2010). Shirashoji et al. (2010) were able to analyze that SHMP influence the texture and meltability possibly due to and enhanced dispersion of the caseins, chelation of $\mathrm{Ca}$ and ion exchange. One of the most important properties of some chelators such as SHMP is their ability to peptize (disperse) the insoluble casein micelle system in natural cheese. They also studied that by increasing the concentration of SMHP, they accounted for higher soluble nitrogen content, which is another indicator of great casein dispersion. This property to disperse caseins depends greatly on $\mathrm{pH}$, the lower the $\mathrm{pH}$ is, the harder it is to disperse the matrix. $\mathrm{A} \mathrm{pH}$ of 5.6 should still be effective to cause dispersion. The addition of SHMP to milk protein concentrates at pH 5.8 increase casein-Ca bound (Mizuno et Lucey, 2005) that they attract from the native CCP, but these new complexes are able to associate with the casein micelles dispersed in the system.

At cooling temperatures these casein micelles are able to re-associate and form a very fine gel network. Johnston and Murphy (1992) reported that milks treated with high concentrations of SHMP had greater casein dispersion and the 
gels made with these treated milks showed improvement in textural properties of the gel. Polyphosphates are also able to complex $\mathrm{Ca}$ and this strong binding property of SHMP results in an increased dispersion of caseins because there is a loss of CCP cross-links that are found in natural cheese. This means that polyphosphates having a strong anionic charge are attracted to other groups with cationic charges such as proteins causing casein micelles to repel each other. In some cases, adding phosphates to milk may cause gelation (Mizuno and Lucey, 2007). However, SHMP is not as effective at gelling caseins as tetrasodium pyrophopshate which is able to form a gel structure over a period of time. One reason for SHMP to inhibit gelation is that it introduces more charge repulsion to the micelles because it has multiple negative. By increasing the concentration of SHMP, it is possible to alter the type and concentration of these new complexes (Ca phosphate salts) formed in the cheese network. Small concentrations of this chelator are not enough to disperse caseins. In cheese, these phosphates that are bound to caseins might have the roll of cross-linking agents by forming bridges within or between caseins, which could make cheese less meltable.

Makhal et al. (2011) postulated the idea of improving the yield of cottage cheese by using tetrasodium pyrophosphate (TSPP) before adding rennet because of its possible ability to bind with proteins and improve moisture holding and the strength of the gel. They also wanted to improve the whey protein content because they hypothesized that there was an interaction between proteins and anionic polyelectrolytes and that they could be incorporated in the 
casein coagulum. This improvement in yield was observed in a previous study by Dybing et al. in 1982 by using SHMP. However, the addition of TSPP did not have a significant effect due to a higher $\mathrm{pH}$ in the milk and protein recovery requires a pH between $3.0-3.2$, which is not desirable because caseins become very soluble past their isoelectric point. Although they are not able to retain whey proteins, pyrophosphates do induce the aggregation of caseins and form a viscous gel, even in solutions and this suggests that pyrophosphate anions that are negatively charged, bind to the positively charged residues of caseins.

Moreover, samples treated with TSPP under certain conditions of $\mathrm{pH}$ and temperature over night, formed a thick gel which could indicate that the caseins dispersed in the milk associated to TSPP anions interacted with each other at a very slow rate and formed the gel. This behavior suggests that some types of phosphates induce gelation under specific conditions by forming some kind of caseinate-Ca phosphate compound. These interactions that cause aggregation, might explain the functionality of processed cheese. Citrates do not appear to have the same effect in the system and act as a cross-linking agent. After chelating the samples with citrates, they noted that they formed soluble complexes. With chelating agents, there is a loss of calcium colloidal phosphates (CCP) and this causes an increase in the dispersion of the casein micelles. When the CCP is partly chelated by TSC, caseins lose attraction because there is less CCP cross linkage and an increase in electrostatic repulsions due to the exposure of phosphoserine residues in the caseins. 
The addition of salt additives affects $\mathrm{Ca}^{2+}$ activity, $\mathrm{CCP}$, the proportion of casein in the micelle, and the ionic strength of the milk, but the relative contributions of each of these factors to the formation of rennet gels is not clear (Udabage et al., 2001). Mizuno et al. (2007) investigated the properties of gels formed by the addition of phosphates such as tetrasodium pyrophosphate (TSPP) and they discovered that gels with high concentrations of salts had the highest breaking force whereas no gels were formed at low concentrations. They were able to see that the breaking force of the gel is also dependent on the concentration of milk protein. At higher concentrations of protein, higher breaking force and a clear network of proteins was formed. These results suggest that TSPP-induced gelation occurs when the added TSPP acts with calcium as a cross-linking agent between dispersed caseins and when the balance between these interactions becomes suitable, caseins aggregate and eventually gel.

Mizuno et al. (2005) studied the cross-linking ability of TSPP in milk protein solutions and suggested that it indeed acts as a cross-linking agent between the caseins and it probably links them more easily or faster that SHMP because unlike SHMP, TSPP only has four charges distributed around its molecule. When chelators are added, they affect the particle size of the casein micelle causing them to dissociate into smaller structures. These dissociated micelles precipitate less easily than intact micelles because those fragments happen to be smaller and lighter. On her study, De Kort (2012) indicates that from all the chelators used in the experiment, SHMP caused the most dissociation in the system after 
addition. Similarly, Panouille et al. (2004) and Potwoski et al. (2008), both analyzed how caseins that are fully dissociated after adding a chelator, can form sub micelles containing between 10 and 15 caseins. Calcium ions in the micelle bind to phosphoserine residues or form part of the CCP complex. When chelators are added, they compete with both the phosphoserine and the CCP for calcium ions in the casein micelle. Chelators have a different affinity for calcium ions to phosphoserine and CCP, which makes them able to release different amounts of CCP from the micelle (De Kort et al., 2009; Mekmene et al., 2009; Turner et al., 2002; Upreti et al., 2006). Furthermore, solubilization of CCP form the micelle, is dependable on the degree of saturation of calcium complexes formed (Holt et al., 1985). For this reason, chelators are able to affect the structure of the micelle to different extents. In milk, the way particles are scattered depends on the concentration, particle size and refractive index relative to the one of the solution. CCP and caseins are mainly responsible for how the casein micelles scatter light (Munyua et al., 1980). When CCP is removed it reduces the ability of caseins to propagate light in the medium, called as refractive index. This index is measured in turbidity. Smiddy et al. (2006) demonstrated that after the addition of $50 \mathrm{mmol}$ L-1 of citrate to skim milk, the light scattering properties of caseins decreased in about $50 \%$. This suggested that all CCP in the cross-linked micelles was removed at this concentration, while the micelle remained intact.

The effect that these calcium chelators have on the physical changes of casein micelles in concentrated micellar casein solutions can be considerably 
different. The increase in viscosity after addition of chelators is normally due to the swelling of caseins, except for SHMP due to its ability to cross-link them. This viscosity can be related to the calcium-ion activity until the casein dissociates into smaller particles and the rate of dissociation depends on the type and concentration of the calcium chelator being used. All these indicators give new opportunities for controlling properties such as viscosity of dairy systems that have a high concentration of proteins. Interactions between calcium and these phosphates must be known to understand the interactions between calcium, phosphate, and casein during the processing of dairy products (De Kort, 2012). 


\section{Hypothesis}

By treating casein micelles found in milk with chelate agents, caseins will be more accessible to enzymic action. This will promote proteolysis, important step for cheese sensory attributes. 


\section{Objectives}

\subsection{General objective}

To determine how the addition of chelating agents such as sodium citrate and sodium hexametaphosphate to a micellar slurry can affect 1) the interaction between caseins and 2) the proteolytic activity of rennet during coagulation and ripening.

\subsection{Specific objectives}

$\checkmark$ To measure protein breakdown of caseins by measuring the amount of water soluble nitrogen.

$\checkmark$ To identify the presence of caseins and smaller peptides on electrophoretic gels by the Urea-PAGE method. 


\section{Materials and Methods}

\subsection{Ingredients}

\subsubsection{Skim milk powder}

Grade A nonfat dry milk made from pasteurized milk was provided by Dairy American.

\subsubsection{Coagulants and proteolytic enzymes}

Two different enzymes were used in this study, rennet with simple strength and a protease which is a purified carboxypeptidase and has application in cheese, enzyme modified cheese, fermented milk products and protein hydrolysates to accelerate ripening among other properties (DSM Food Specialties).

\subsubsection{Micellar casein powder}

An $85 \%$ micellar casein powder Glanbia Foods, Inc. was used for the second phase of the ecperiment.

\subsubsection{Chelators}

Two different chelators were used at three different concentrations:

- Sodium hexametaphosphate (NaHMP) at 2.5, 3.2, and $10 \mathrm{mM}$ (Mizuno et al., 2007). provided by ICL Performance Products.

- Sodium citrate (SC) at 5,15, and $25 \mathrm{mM}$ (Tong et al., 2014) provided by Tate and Lyle. 


\subsection{Sample preparation}

This thesis studied the effect of chelating agents on proteolysis in two different phases. The first phase consisted of a first experiment called preliminary trials and the second phase consisted of a second experiment, which is the main study in this research.

\subsubsection{First experiment (preliminary trials)}

As part of this study, preliminary trials were performed to establish what chelators would be used, their concentration, and the effect of rennet on chelated milk samples.

\subsubsection{Reconstitution of milk powder}

Seven samples were prepared by reconstituting skim milk powder at $10 \%$ $(\mathrm{w} / \mathrm{v})$ for a total volume of $50 \mathrm{ml}$ and mixed for $20 \mathrm{~min}$ at $280 \mathrm{rpm}$ at room temperature.

\subsubsection{Addition of chelators}

- NaHMP was added to three milk samples at three different concentration levels (2.5, 3.2, and $10 \mathrm{mM}$ ) (Mizuno et al., 2007).

- SC was added to three samples at three concentration levels $(5,15,25$ mM) (Tong et al., 2014). All samples were homogenized on a stirring plate 
for 20 minutes at room temperature. The $\mathrm{pH}$ was adjusted to 6.7 with $\mathrm{HCl}$ $0.1 \mathrm{~N}$.

\subsubsection{Addition of coagulant}

Rennet was diluted with 20 parts of DI water to 1 part of coagulant before adding it to all six milk samples (Upreti, 2006) and held in a water bath at $32^{\circ} \mathrm{C}$ to monitor coagulation time. Samples were compared to a control which consisted of reconstituted skim milk and rennet.

\subsection{Second experiment}

\subsubsection{Preparation of micellar casein slurries}

Ten samples of $25 \mathrm{~g}$ of micellar casein solution were prepared at $25 \%$ protein content similar to cheese with $28.4 \mathrm{~g}$ of powder and $71.59 \mathrm{~g}$ of DI water. Individual slurries were prepared with the previous solutions that consisted of $16.25 \mathrm{~g}$ of micellar casein solution, $1.25 \mathrm{~g}$ of $\mathrm{NaCl}$ and $7.5 \mathrm{~g}$ of DI water each. These slurries were divided into two treatment groups. The first group consisted of four slurries treated with chelators and one control with no treatment. The second group consisted of four slurries treated with chelators and a rennet/protease solution, and one control treated with only rennet. 


\subsubsection{Addition of chelators}

NaHMP was added to four micellar casein slurries at two different concentration levels (2.5 and $10 \mathrm{mM}$ ) (Mizuno et al., 2007).

SC was added to another four micellar casein slurries at two concentration levels (5 and $25 \mathrm{mM}$ ) (Tong et al., 2014). All samples including the control were homogenized on a stirring plate for 20 minutes at room temperature. Subsequently the $\mathrm{pH}$ of all samples was adjusted to 5.2 with lactic acid $10 \%(\mathrm{v} / \mathrm{v})$ (Jaros et al., 2008). This is the $\mathrm{pH}$ found in cheese after rennet and proteolytic activity under ripening conditions.

\subsubsection{Addition of rennet/protease solution}

Five samples of the ten micellar casein slurries were treated with $0.75 \mathrm{ml}$ of protease were added to right before rennet (DSM Food Specialties). Subsequently, rennet was diluted 20 parts to 1 with DI water and added to the slurry (Upreti, 2006).

\subsection{Analytical methods}

\subsubsection{Preliminary coagulation studies (first experiment)}

Coagulation time was measured for all fluid milk samples held in a water bath at $35^{\circ} \mathrm{C}$ and compared to control. This test was determined by measuring the time it took for a gel structure to appear once the coagulant was added to the 
fluid milk. Subsequently, the difference between gel structures of the samples were measured descriptively.

\subsubsection{Urea-PAGE electrophoresis}

The presence of broken down peptides was measured with the Urea-PAGE method after the incubation period in the water bath. Ten mg of each sample were mixed with $1 \mathrm{~mL}$ of a Tris/urea buffer and then held in a water bath at $50^{\circ} \mathrm{C}$ for 5 min. Subsequently, $4 \mu \mathrm{L}$ of sample were loaded into a $10 \%$ Mini-Protean TGX precast gel (BIO RAD Laboratories, Inc.) and ran in a Tris-glycine buffer at 150V for about 90 min. Gels were stained with Coomassie Brilliant Blue R-250 (BIO RAD Laboratories, Inc.) and washed with a distain solution (40\% methanol, $50 \%$ DI water, and 10\% acetic acid) over night. Lastly, gels were scanned with a Molecular Imager Gel Doc XR (BIO RAD Laboratories, Inc.) and the density of the bands was analyzed with ImageJ scientific image analysis software to identify the presence of peptides due to proteolysis.

\subsection{Second experiment}

\subsubsection{Extraction of water soluble nitrogen fractions}

All then samples were incubated at $32^{\circ} \mathrm{C}$ to activate the proteolytic enzymes and accelerate ripening conditions. In order to register any changes during the incubation period of the slurry, total nitrogen (TN) and water soluble nitrogen 
(WSN) were measure before and after incubation. To measure TN, 5 grams of treated micellar casein slurry were analyzed with the Kjeldahl method.

Simultaneously, another ten grams of slurry were homogenized with $20 \mathrm{~mL}$ of distilled water on a vortex mixer (Fisher Scientific, Cat No. 02215365, USA) for $30 \mathrm{~s}$. The homogenized mixtures were then held in a water bath at $40^{\circ} \mathrm{C}$ for 20 min (Juan et al., 2010). Subsequently, the samples were centrifuged at $4000 \mathrm{rpm}$ for $20 \mathrm{~min}$ at $4^{\circ} \mathrm{C}$. The supernatant was finally filtered through glasswool (Bütikofer et al., 1993) and Whatman filter paper number 1 (Juan et al., 2010).

The nitrogen content of the samples was determined following the Kjeldahl protocol. Water-soluble nitrogen was determined as a percentage of the total nitrogen in the samples.

\subsubsection{Urea-PAGE electrophoresis}

The presence of broken down peptides was measured with the Urea-PAGE method before and after the incubation period. Ten mg of each slurry sample were mixed with $1 \mathrm{~mL}$ of a Tris/urea buffer and then held in a water bath at $50^{\circ} \mathrm{C}$ for 5 min. Subsequently, $4 \mu \mathrm{L}$ of sample were loaded into a $10 \%$ Mini-Protean TGX precast gel (BIO RAD Laboratories, Inc.) and ran in a Tris-glycine buffer at 150V for about $90 \mathrm{~min}$. Gels were stained with Coomassie Brilliant Blue R-250 (BIO RAD Laboratories, Inc.) and washed with a distain solution (40\% methanol, $50 \%$ DI water, and 10\% acetic acid) over night. Lastly, gels were scanned with a Molecular Imager Gel Doc XR (BIO RAD Laboratories, Inc.) and the density of 
the bands was analyzed with ImageJ scientific image analysis software to identify the presence of peptides due to proteolysis.

\subsection{Statistical analysis}

\subsubsection{Water Soluble Nitrogen (\%WSN)}

The sample treatments present in this study were run and analyzed in duplicate. Analysis of variance, two-way ANOVA, was applied to the experimental data $(n=8)$ using the general linear model to assess water soluble nitrogen. The analysis was conducted using the JMP 12.1.0 software. All differences were considered statistically significant at $p \leq 0.01$.

\subsubsection{Urea-PAGE electrophoresis}

The difference between densities in the bands of Urea-PAGE gels were analyzed using a ANOVA analysis of variance to determine if there were any significant patterns on the separation of caseins. 


\section{Results}

\subsection{Preliminary coagulation studies (first experiment)}

After the addition of chelators and rennet to fluid milk samples, coagulation time (CT) was measured. Table 1 shows the CT for all samples.

\section{Table 1. Coagulation time for fluid milk samples treated with NaHMP, SC} and rennet.

\section{Sample}

Control (untreated)

SHMP $2.5 \mathrm{mM}$

SHMP $10 \mathrm{mM}$

SC $5 \mathrm{mM}$

SC $25 \mathrm{mM}$

RSHMP $2.5 \mathrm{mM}$

RSHMP $10 \mathrm{mM}$

RSC $5 \mathrm{mM}$

RSC $25 \mathrm{mM}$

\section{CT (min)}

$45 \min$ 
After treated samples were incubated, the gel structure of the samples was visually characterized and described. Figures 1-5 show the effect of chelating agents on reconstituted skim milk powder with and without rennet. These samples were compared to a control consisting of coagulated reconstituted skim milk powder. Samples were also centrifuged with and without the addition of rennet as a quick test to identify any kind of sediment or structure formed during renneting. Figures 6-9 show the difference between centrifuged renneted skim milk with chelators and without chelators.

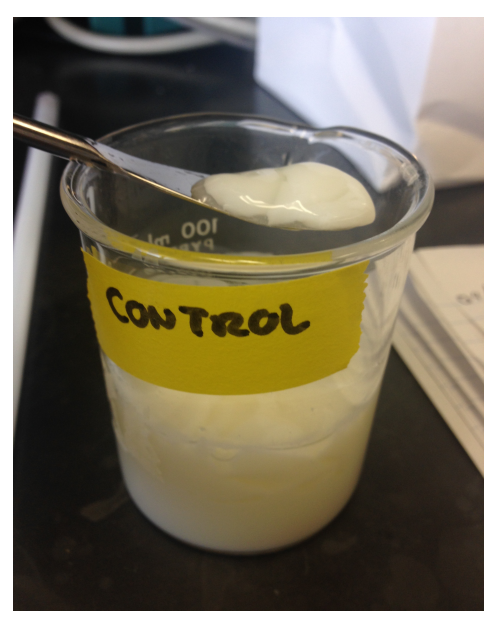

Figure 7. Reconstituted skim milk powder coagulated with rennet.

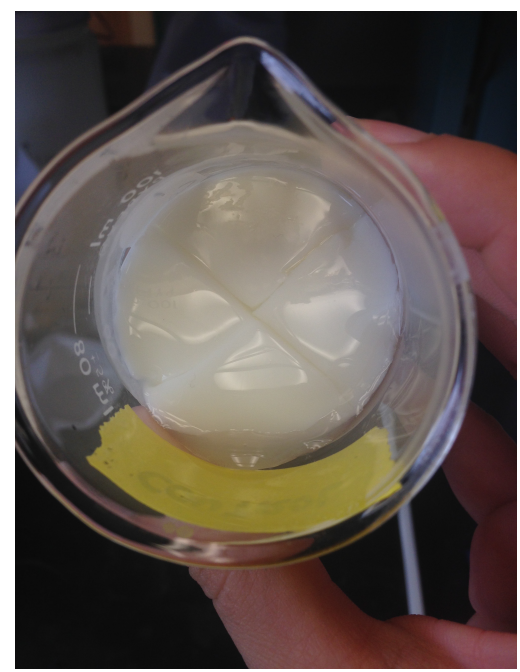

Figure 8. Reconstituted skim milk powder coagulated with rennet.

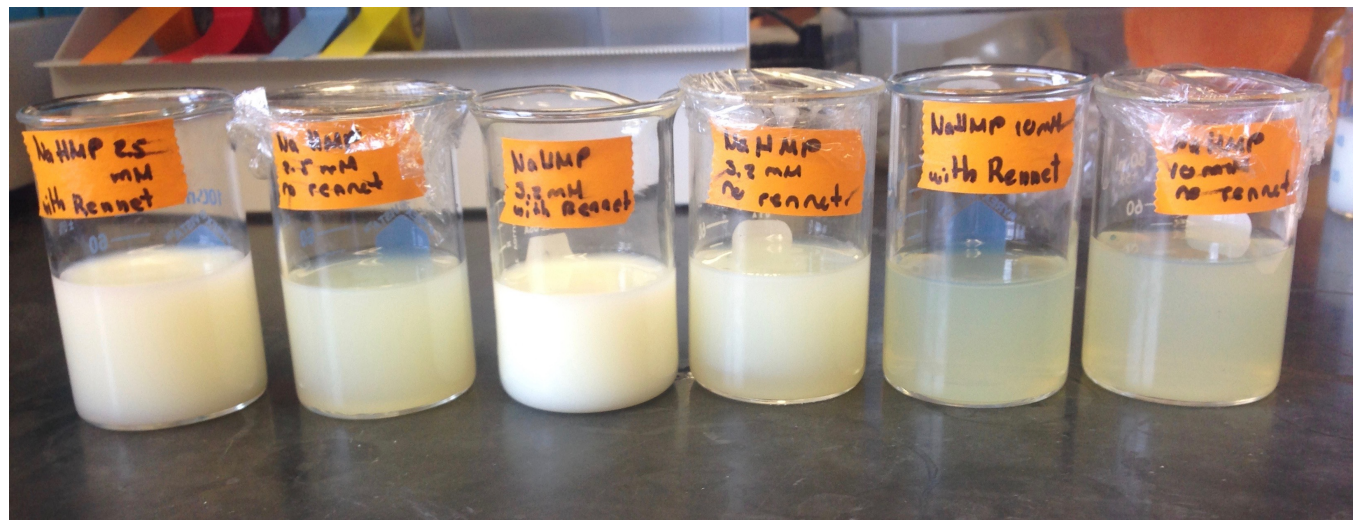

Figure 9. Example of the effect of SHMP on reconstituted skim milk powder. From left to right, skim milk with $2.5 \mathrm{mM}$, skim milk with $2.5 \mathrm{mM}$ and rennet, skim milk with $3.2 \mathrm{mM}$, skim milk with $3.2 \mathrm{mM}$ and rennet, skim milk with $10 \mathrm{mM}$, skim milk with $10 \mathrm{mM}$ and rennet. 


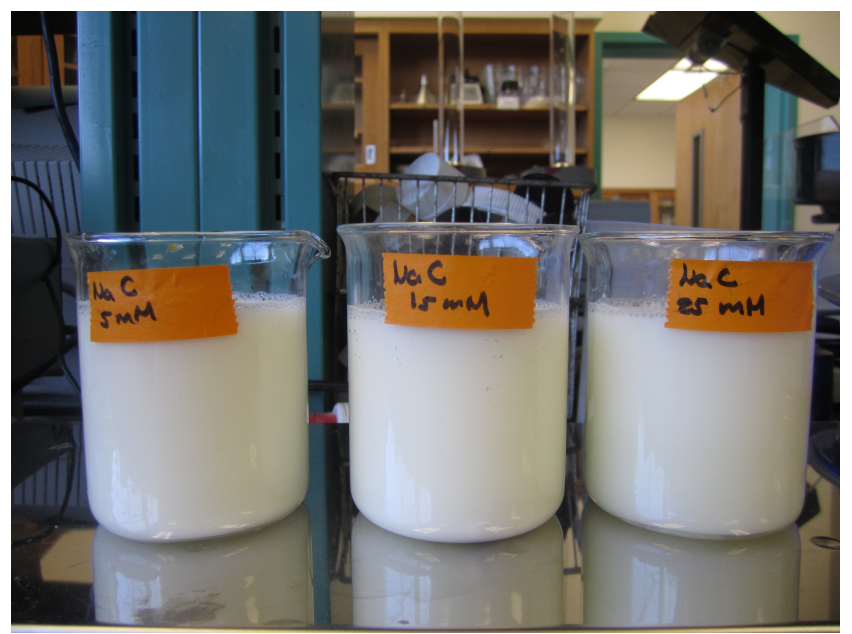

Figure 10. Effect of sodium citrate on reconstituted skim milk. From left to right: sample 1 skim milk with $5 \mathrm{mM}$, sample 2 skim milk with $15 \mathrm{mM}$ and sample 3 skim milk with $25 \mathrm{mM}$.

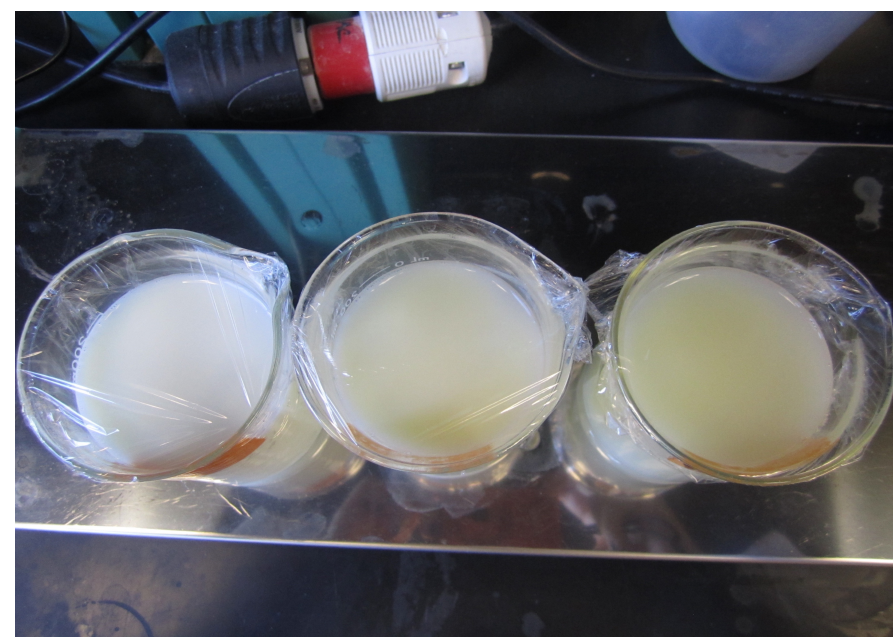

Figure 11.Effect of sodium citrate on reconstituted skim milk powder at three different concentrations. From left to right the concentrations used were 5,15 , and $25 \mathrm{mM}$. 


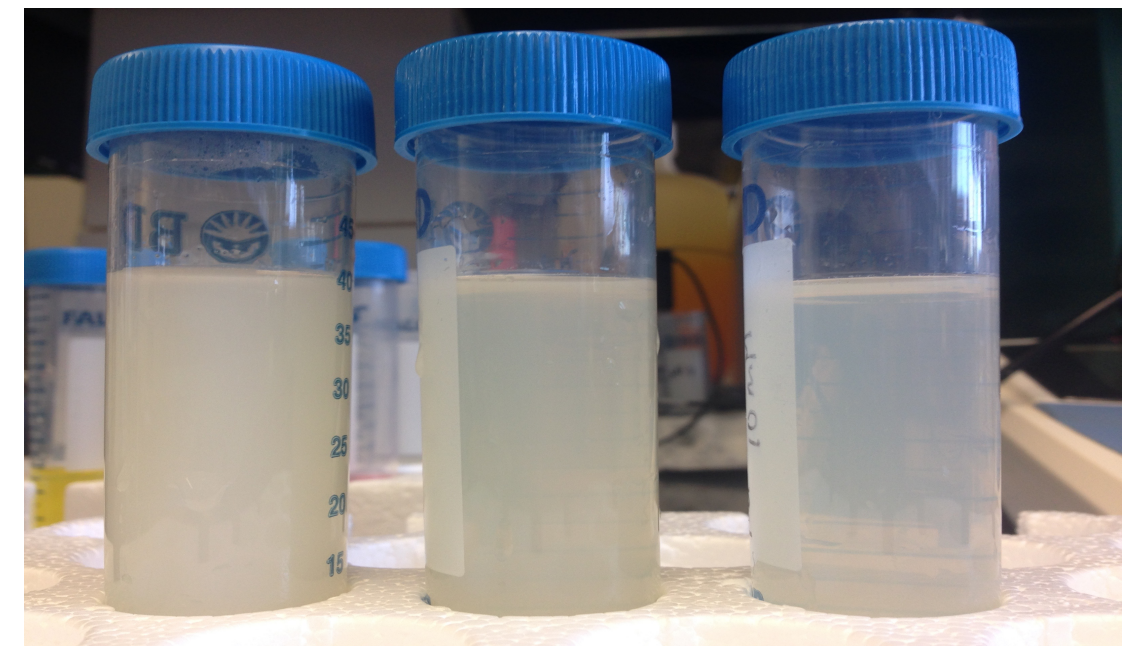

Figure 12. Effect of SHMP on reconstituted skim milk powder at $2.5,3.2$, and $10 \mathrm{mM}$. The order of concentrations is from left to right.

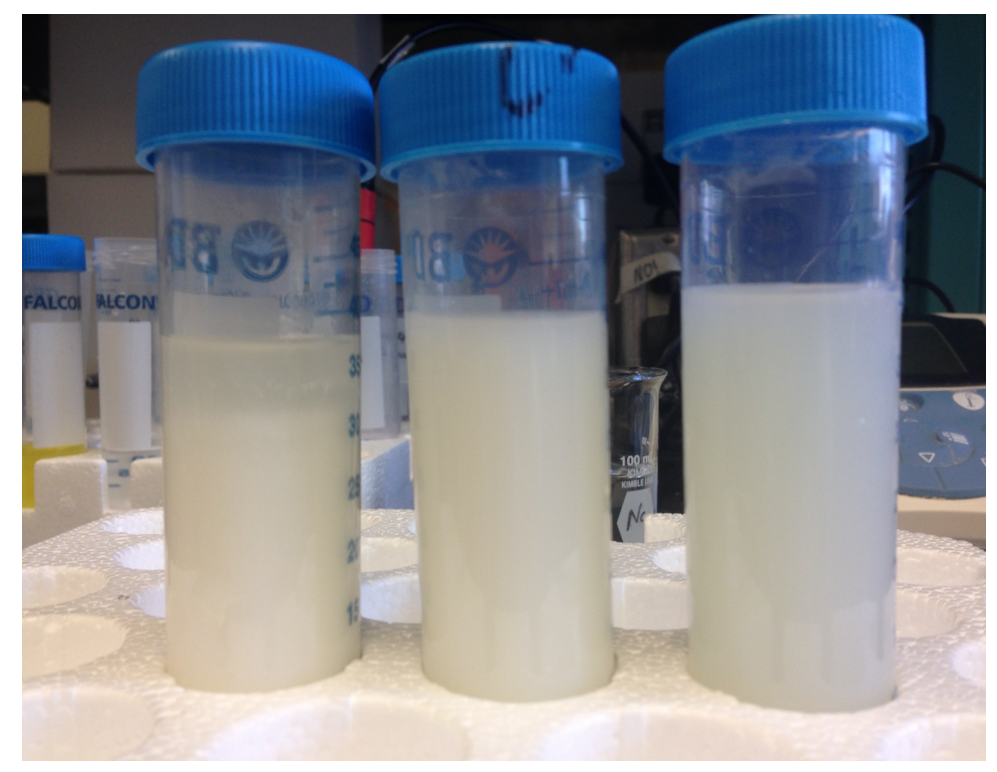

Figure 13. Effect of SC on reconstituted skim milk powder at 5,15 , and $25 \mathrm{mM}$ (left to right). 


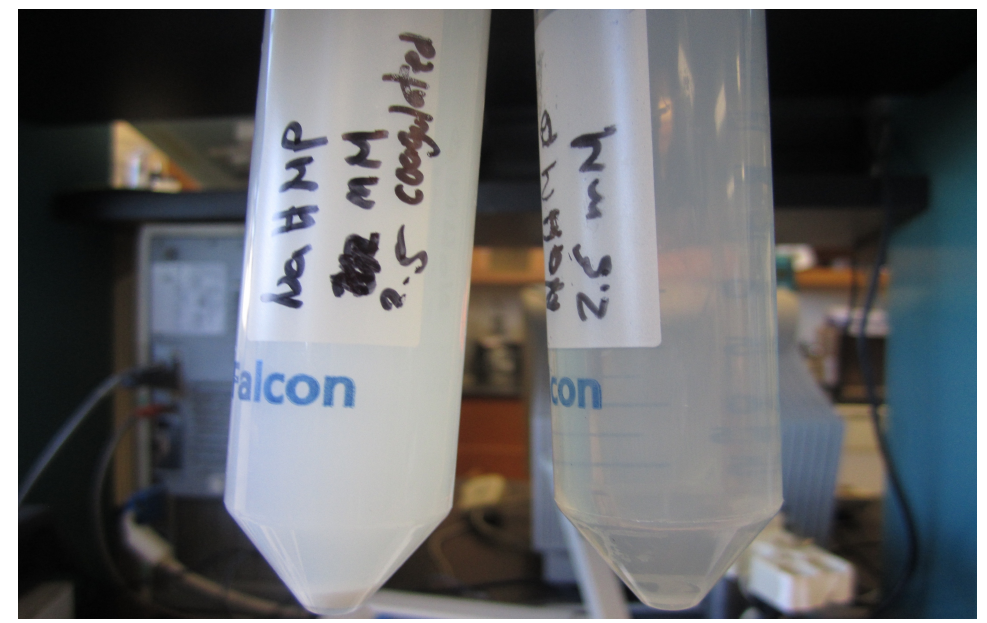

Figure 14. Effect of SHMP at $2.5 \mathrm{mM}$ on reconstituted skim milk powder after centrifugation with rennet and no rennet added (left to right respectively).

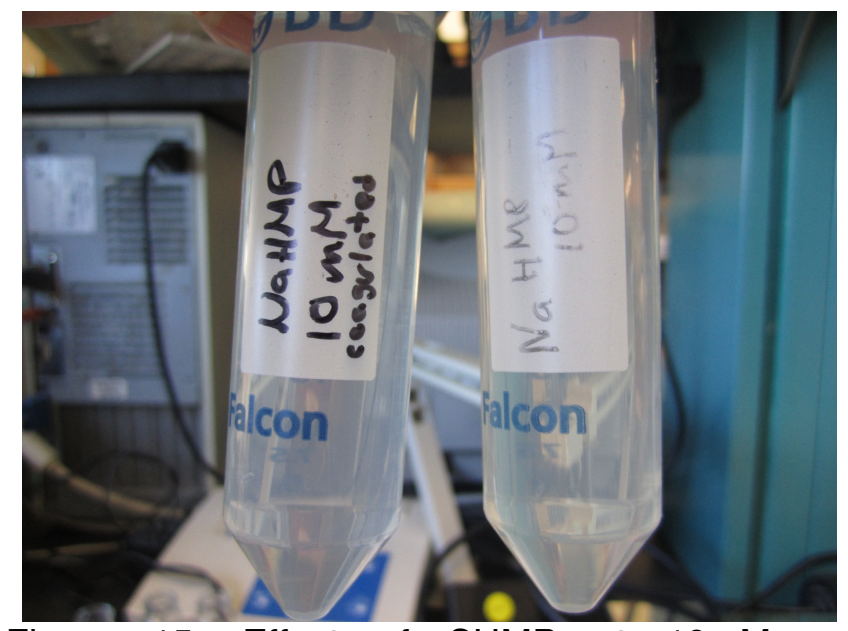

Figure 15. Effect of SHMP at $10 \mathrm{mM}$ on reconstituted skim milk powder after centrifugation with rennet and no rennet added (left to right respectively). 


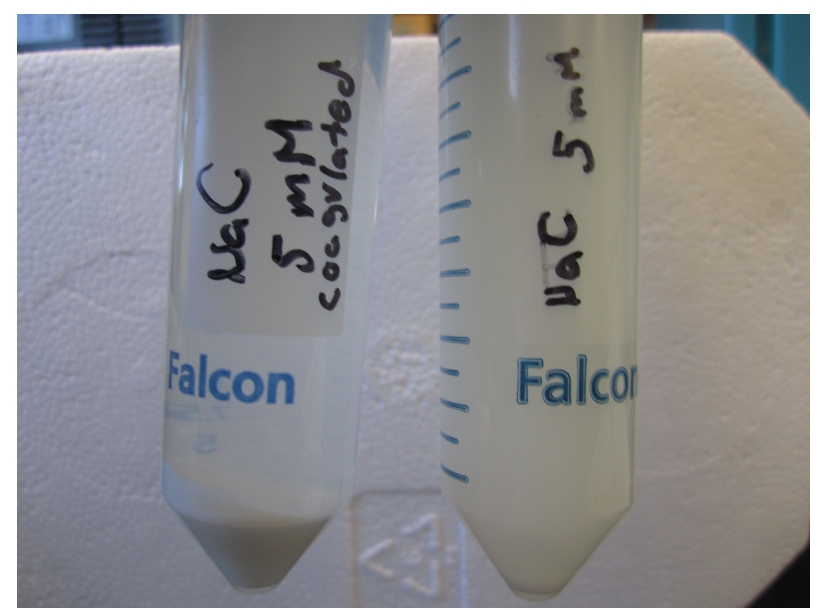

Figure 16. Effect of $\mathrm{SC}$ at $5 \mathrm{mM}$ on reconstituted skim milk powder after centrifugation with rennet and no rennet added (left to right respectively).

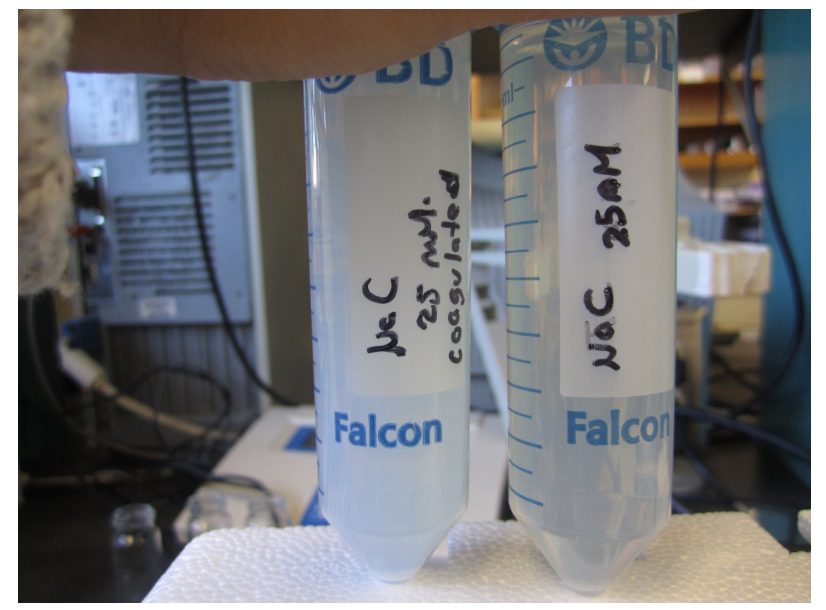

Figure 17. Effect of SC at $25 \mathrm{mM}$ on reconstituted skim milk powder after centrifugation with rennet and no rennet added (left to right respectively). 


\subsubsection{Urea-PAGE electrophoresis}

For the preliminary tests of this research, electrophoresis gels were analyzed on reconstituted skim milk. Figure 18 shows milk sample treated with SHMP and SC at different concentrations. Rennet milk was used as the control to compare density of bands.

Figure 19 bellow shows casein samples treated with SHMP and SC at three different concentrations and rennet.

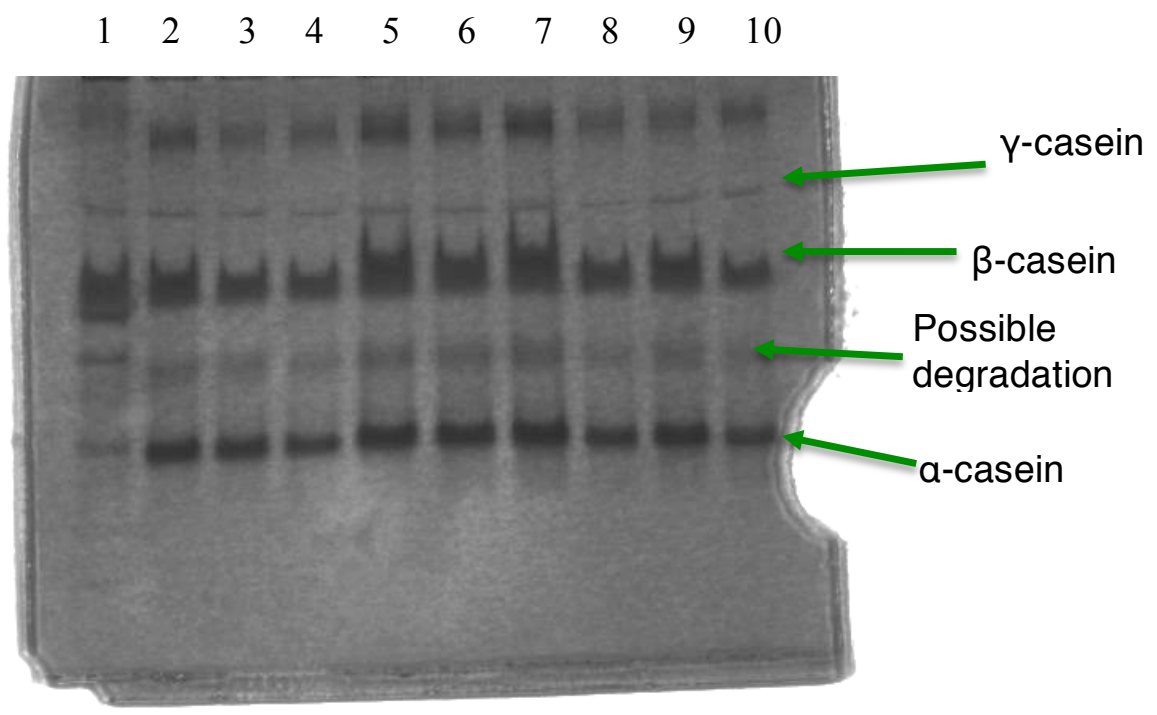

Figure 18. Representative Urea-PAGE gel of reconstituted skim milk samples; lane 1 rennet milk (control); lanes 2-4 SHMP at 3 levels $(2.5,3.2$, $10 \mathrm{mM})$ and lanes $8-10 \mathrm{SC}$ at 3 levels $(5,15,25 \mathrm{mM})$. 


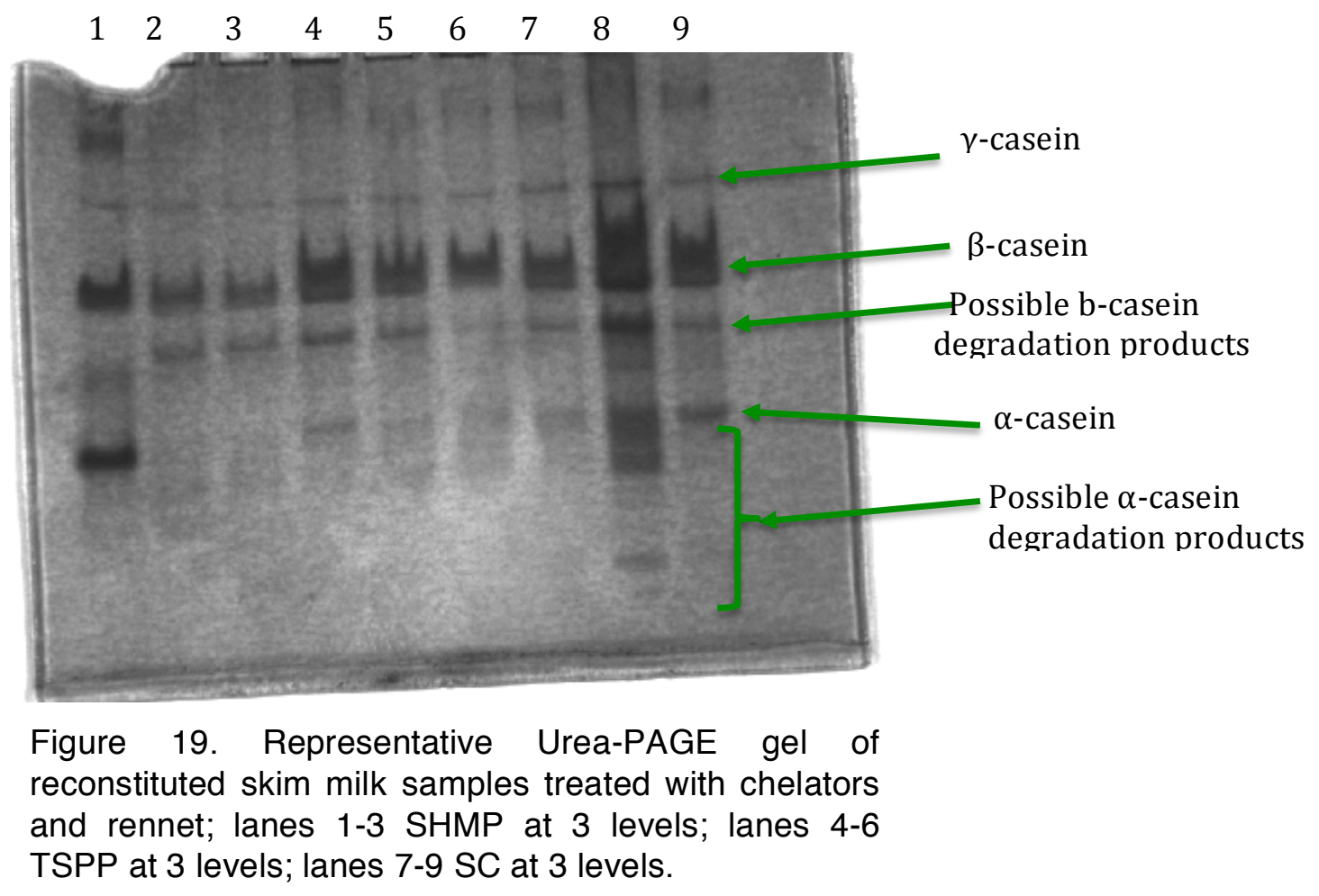

\subsection{Second experiment}

\subsubsection{Water soluble nitrogen (\%WSN)}

Water soluble nitrogen was analyzed in micellar casein slurries in two treatment groups: chelated slurries and chelated slurries with proteolytic enzymes before and after incubation under accelerated ripening conditions as a measurement of enzymatic activity to break down caseins into smaller peptides.

After reporting the percentage of WSN for each treatment group, an ANOVA analysis was performed to identify any significant difference in the proteolytic activity between treatments at a significance level of $a=0.05$. Table 3 shows the ANOVA analysis with the significance of each factor and their interactions after the incubation period of the samples. The first factor being the two chelators 
(SHMP and SC), the second factor being the levels of the chelators (high and low); and the third factor being the presence or absence of enzyme. From the combinations of the three factors, we have eight treatment groups. The response variable is a log transformation applied to the percentage of WSN in order to correct unequal variances between the treatments. The effect on the data after the log transformation is shown in Figures 21 and 22 which show the distribution of the ANOVA residuals before and after the log transformation. The analysis in Table 3 shows marginal evidence of differences in WSN between chelators $(p=0.075)$, but not enough to be statistically significant at $a=0.05$.

\section{Table 2. ANOVA table with log transformation for treatment effects after incubation period.}

\begin{tabular}{lccc}
\hline Source & DF & F Ratio & Prob > F \\
Chelator & 1 & 3.6983 & 0.0750 \\
Level & 1 & 0.9686 & 0.3417 \\
Chelator ${ }^{*}$ Level & 1 & 0.3181 & 0.5817 \\
Enzyme & 1 & 2.2573 & 0.1552 \\
Chelator ${ }^{\star}$ Enzyme & 1 & 0.0855 & 0.7742 \\
Level ${ }^{*}$ Enzyme & 1 & 1.6019 & 0.2263 \\
Chelator ${ }^{*}$ Sample*Enzyme & 1 & 0.1280 & 0.7258 \\
\hline
\end{tabular}




\section{Residual by Predicted Plot}

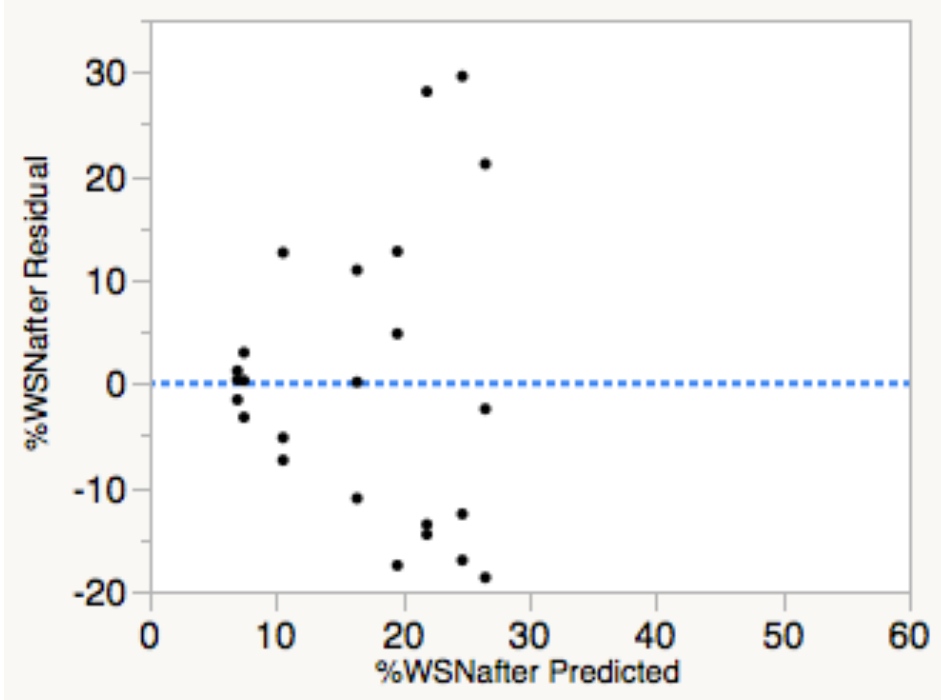

Figure 20. Residuals vs predicted values of \%WSN after incubation period.

Residual by Predicted Plot

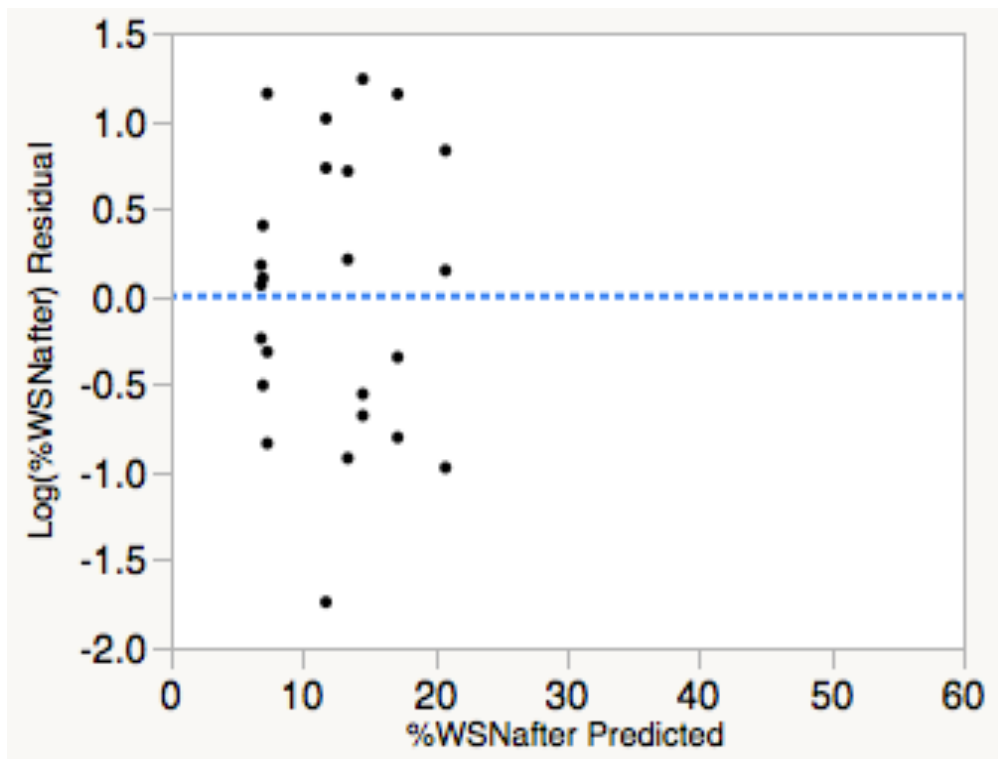

Figure 21. Residuals vs predicted values of \%WSN after incubation period with log transformation. 


\subsubsection{Urea-PAGE electrophoresis}

Electrophoresis was performed on the micellar casein slurries treated with chelating agents and proteolytic enzymes with the objective of identifying major caseins and possible degradation products. Each band represents these caseins and their densities were measured before and after the incubation period. It is expected to see differences in the percentages of each casein present before and after incubation due to proteolysis. It was also of interest in this research to analyze the effect of each treatment on the percentage of each major casein. The following tables and figures show Urea-PAGE gels of the treatment groups. The effect of the factors was compared using ANOVA to identify significant differences.

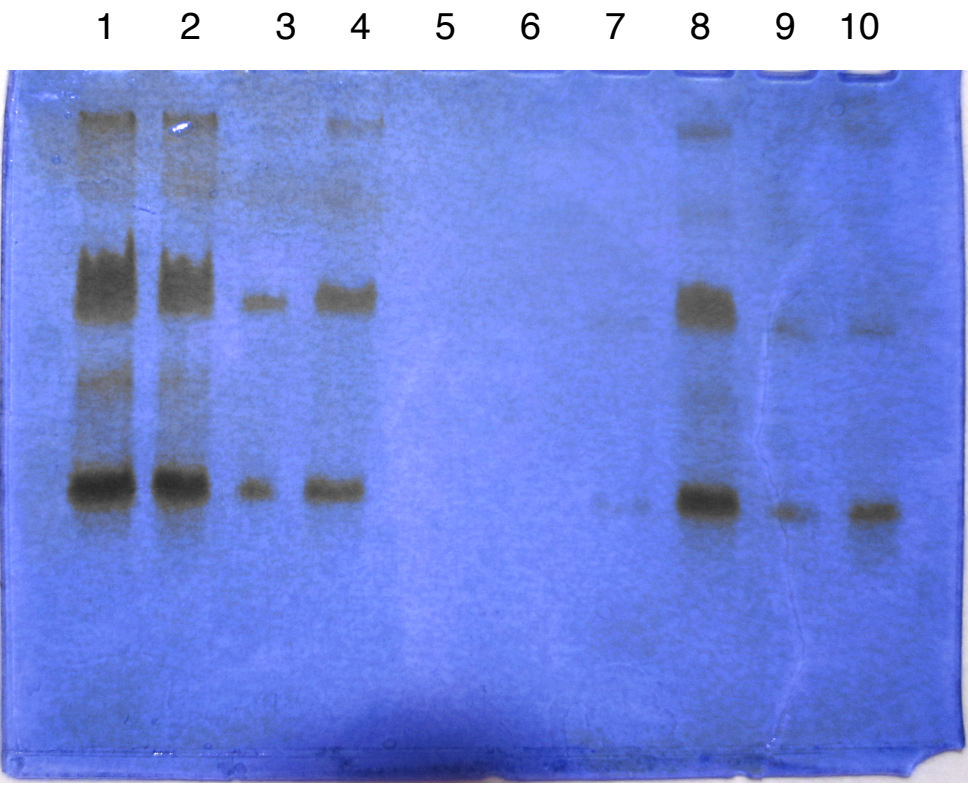

Figure 22. Representative Urea-PAGE gel of micellar casein slurry treated with SHMP (lanes 2 and 3 ) and SC (lanes 4 and 8) at two different concentrations, 2.5 and $10 \mathrm{mM}$; and 5 and $25 \mathrm{mM}$ respectively before incubation. Lane one is the control. 


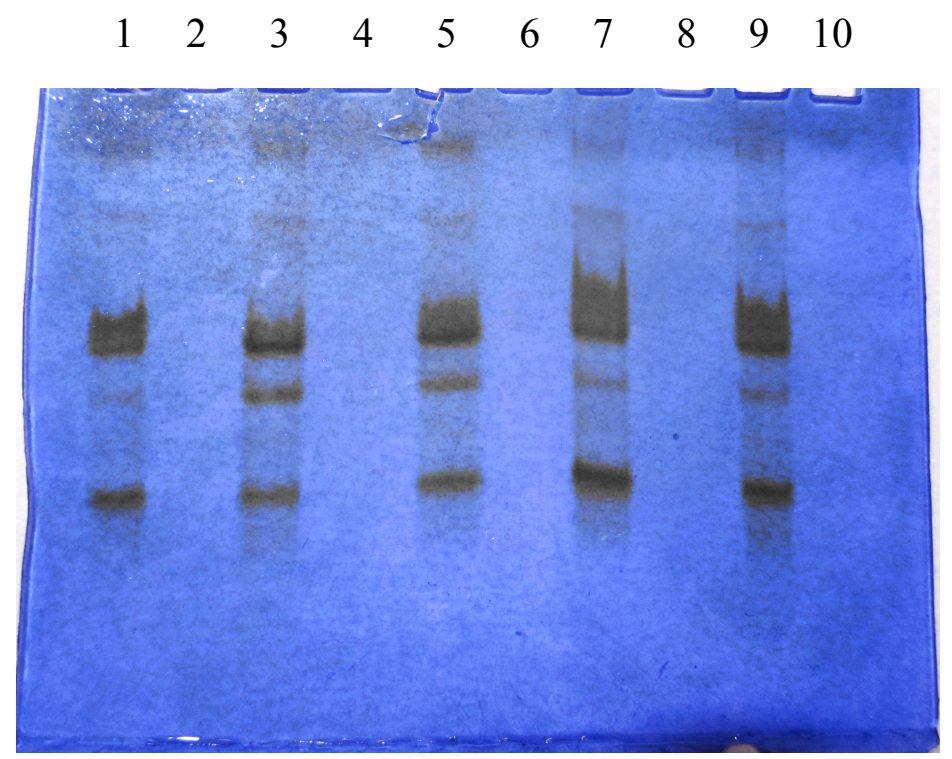

Figure 23. Representative Urea-PAGE gel of micellar casein slurry treated with SHMP (lanes 3 and 5) and SC (lanes 7 and 9) at two different concentrations, 2.5 and $10 \mathrm{mM}$; and 5 and $25 \mathrm{mM}$ respectively before incubation with addition of proteolytic enzymes. Lane one is the control.

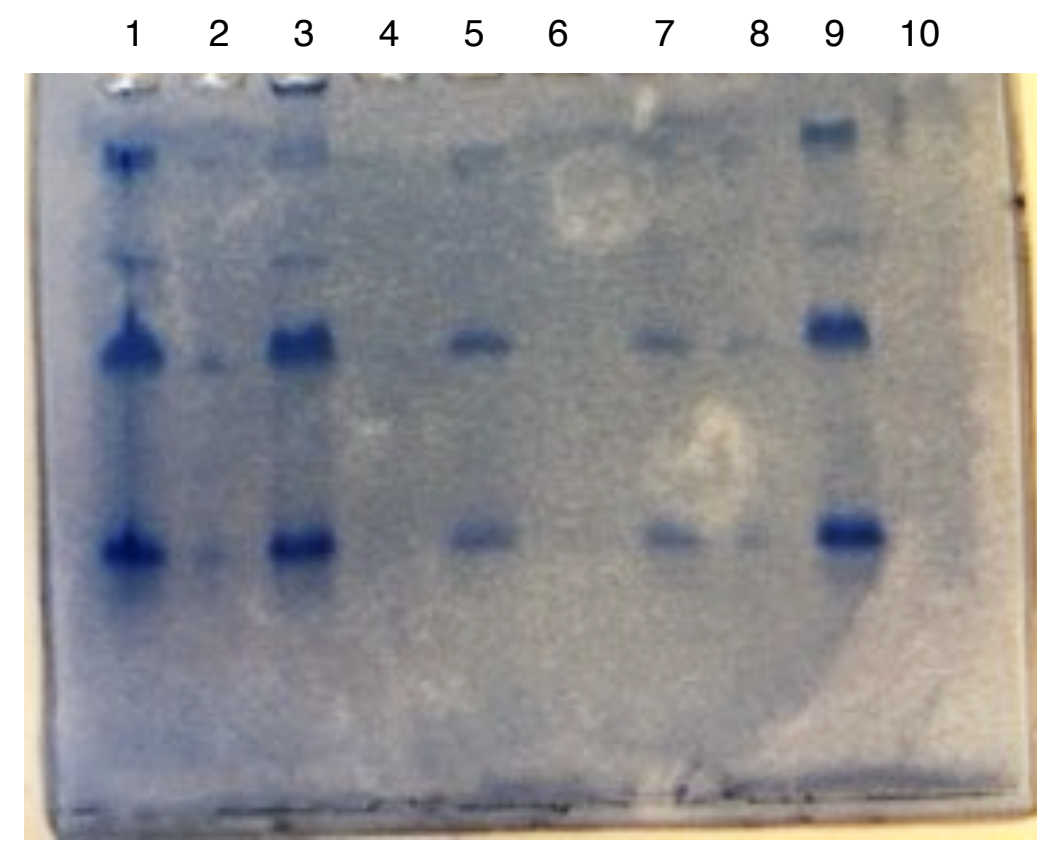

Figure 24. Representative Urea-PAGE gel of micellar casein slurry treated with SHMP (lanes 3 and 5) and SC (lanes 7 and 9) at two different concentrations, 2.5 and $10 \mathrm{mM}$; and 5 and $25 \mathrm{mM}$ respectively after incubation. Lane number one is the control. 


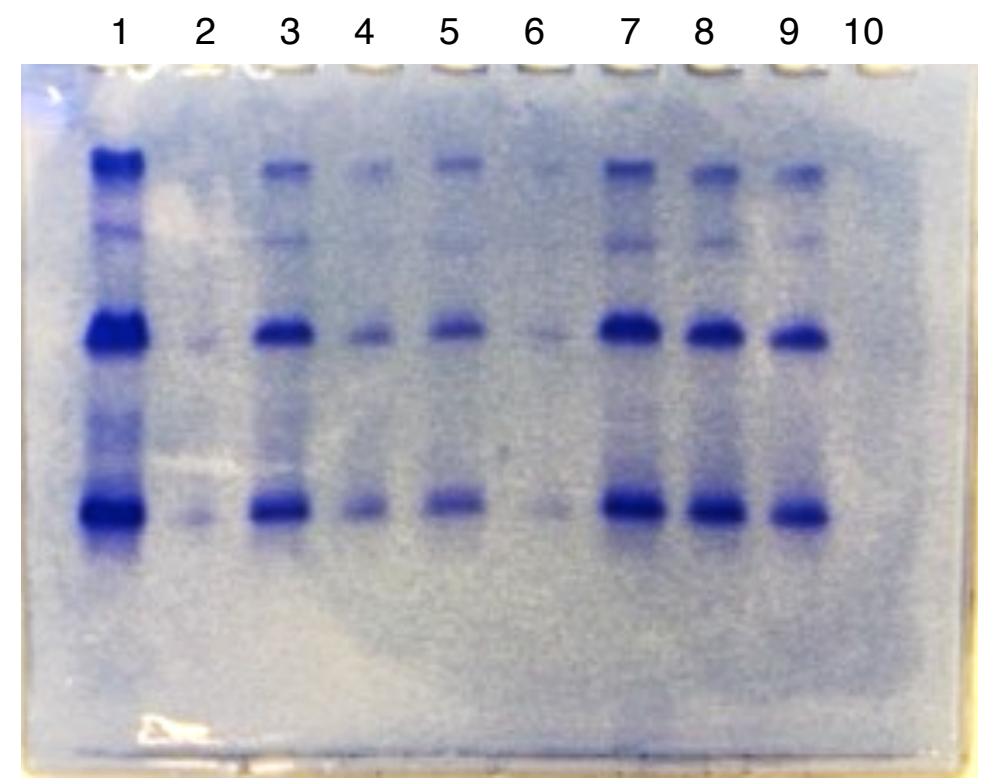

Figure 25. Representative Urea-PAGE gel of micellar casein slurry treated with SHMP (lanes 3 and 5) and SC (lanes 7 and 9) at two different concentrations, 2.5 and $10 \mathrm{mM}$; and 5 and $25 \mathrm{mM}$ respectively and proteolytic enzymes after incubation. Lane one is the control.

After performing gel electrophoresis, the density if the bands was measured with image $\mathrm{J}$ were each lane on the gel was plotted and the higher peaks were identified as the major caseins present in the system. Figure 27 shows a representation of the plot obtained with the software.

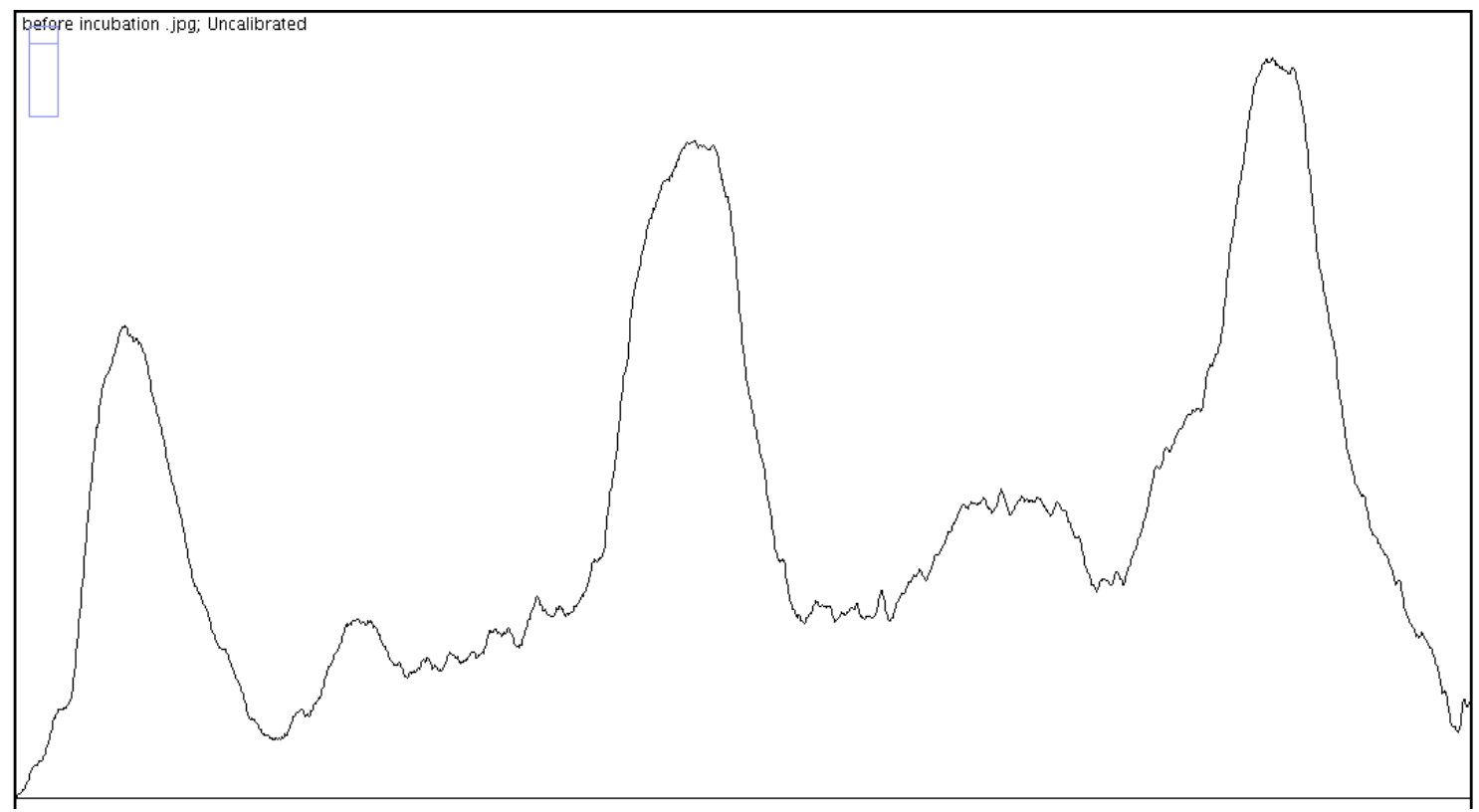

Figure 26. Representative lane plot of Urea-PAGE electrophoresis gels with image J. Higher peaks represent major caseins present in the system Gamma, beta and alpha from left to right respectively. 
Tables 4-9 show the ANOVA results and the Tukey's comparisons for the difference in the percentages before and after incubation for gamma, beta and alpha caseins respectively. The data shows statistical significant difference at a $5 \%$ level.

Table 3. ANOVA for the difference between treatments before and after incubation for gamma casein.

\begin{tabular}{lrrr}
\hline Source & DF & F Ratio & Prob $>$ F \\
Treatment & 4 & 3814.652 & $<.0001^{*}$ \\
Enzyme & 1 & 2011.826 & $<.0001^{*}$ \\
Treatment*enzyme & 4 & 717.1291 & $<.0001^{*}$ \\
\hline
\end{tabular}

Table 4. Tukey's comparison for the effect of the interaction of chelator and enzyme level on the percentage of gamma casein.

\section{Level}

NaHMP 10,yes

SC 5,yes

NaHMP 10,no

SC 5,no

NaHMP 2.5,no

Control,yes

NaHMP 2.5,yes

Control,no

SC 25,yes

SC 25 , no
Least Sq Mean

A

B

B

C

11.36827

10.93358

9.27713

8.42511

E

6.73046

5.13612

3.94762

3.28779

$\mathrm{H}$ 
Table 5. ANOVA for difference between treatments before and after incubation for beta casein

\begin{tabular}{lrrr}
\hline Source & DF & F Ratio & Prob $>$ F \\
Treatment & 4 & 129.8696 & $<.0001^{*}$ \\
Enzyme & 1 & 245.3693 & $<.0001^{*}$ \\
treatment*enzyme & 4 & 39.4745 & $<.0001^{*}$ \\
\hline
\end{tabular}

Table 6. Tukey's comparison for the effect of the interaction of chelator and enzyme level on the percentage of beta casein.

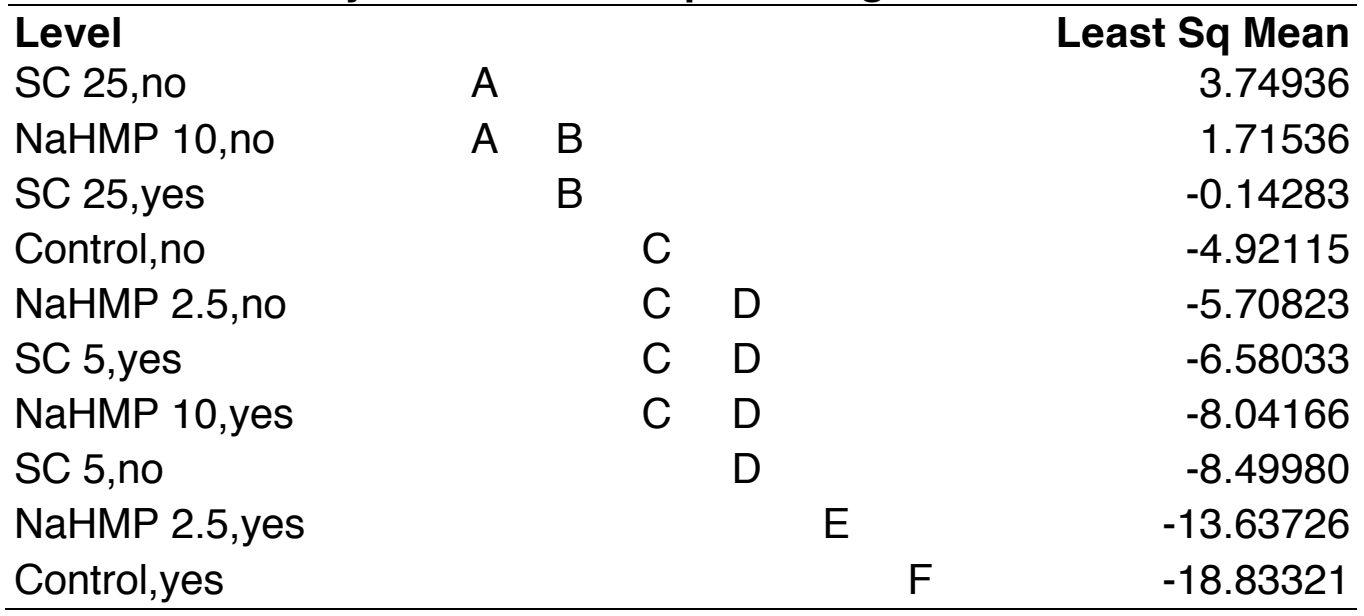

Table 7. ANOVA for differences between treatments before and after incubation for alpha caseins

\begin{tabular}{lrrr}
\hline Source & DF & F Ratio & Prob $>$ F \\
Treatment & 4 & 264.2652 & $<.0001^{*}$ \\
Enzyme & 1 & 44.6553 & $<.0001^{*}$ \\
treatment ${ }^{*}$ enzyme & 4 & 93.0964 & $<.0001^{*}$
\end{tabular}


Table 8. Tukey's comparison for the effect of the interaction of chelator and enzyme level on the percentage of alpha casein.

Level

Control,yes

NaHMP 2.5,yes

SC 25,no

Control,no

SC 5,no

NaHMP 2.5,no

SC 25,yes

SC 5,yes

NaHMP 10,yes

NaHMP 10,no
Least Sq Mean

A

B

12.10275

8.50115

C $\quad 3.54261$

C D 0.97354

D $E$

E $F$

E $F$

$-0.77733$

$-2.71688$

$-3.14497$

$\mathrm{F}$

$-4.78795$

G $\quad-11.37060$

G $\quad-12.64894$ 


\section{Discussion}

\subsection{Preliminary coagulation studies (first experiment)}

As shown in table 1, coagulation time was measured in reconstituted skim milk with the addition of chelators and rennet. Only the control and samples treated with sodium citrate and rennet showed a gel network after 45, 90 and a 100 min respectively. As discussed earlier in chapter 1, most chelating agents sequester calcium, which has a relevant role in protein aggregation. They prevent aggregation and formation of a gel structure. This could be because coagulation did not occur due to the shift in calcium equilibrium in the system. It has been studied that some chelating slats can bind strongly to caseins and form a structure similar to a gel after a long period of time. Regular cow milk is expected to coagulate by the effect of rennet after about 40 minutes. When adding chelators, this enzymatic activity is interrupted. As seen in Figures 9, 12, 14 and 15 , SHMP is a strong chelator that changes properties in milk drastically. However it was observed that milk was able to form a weaker gel after over an hour when sodium citrate was added. Jenkins (1983) carried out a study about the effect of fatty acids and chelating agents on rennet clotting skim milk. Several experiments were performed and one of them analyzed the effect of citrate on rennet-casein clot formation. His study showed that $15 \mathrm{mM}$ in $10 \%(\mathrm{w} / \mathrm{v})$ reconstituted skim milk was completely effective in preventing clotting at a $\mathrm{pH}$ of 6.1 but as the latter decreased to between 5.2 and 5.1, it was not as effective and partial or complete clotting could occur. The study suggests that at the $\mathrm{pH}$ 
naturally occurring in calf abomasum, $15 \mathrm{mM}$ citrate may be able to inhibit clotting but not completely prevent it from happening, therefore, formation of curd may occur. This study coincides with some of the preliminary observation revealed in this thesis research where we were able to observe a weaker gel network formed in rennet milk treated with sodium citrate.

\subsubsection{Urea-PAGE electrophoresis}

During the preliminary coagulation studies, a few density measurements were performed. However, the test was carried only after the incubation period. No data was reported before incubation. This meant that there was no way of detecting a difference or change in the percentages of caseins present on the gels. Therefore it was not possible to take this data into consideration to carry an ANOVA test to confirm proteolytic activity and report real differences between treatments before and after incubation. Nevertheless, Figures 18 and 19 serve as a visual aid to understand how proteins in milk that have been broken down to some extent may appear on a gel and what other elements may be considered as degradation products for their further study. 


\subsubsection{Second experiment}

\subsubsection{Water soluble nitrogen (\%WSN)}

Water is one of the most common solvents implemented to measure the amount of nitrogen present in a cheese specially during ripening due to the proteolytic activity responsible for hydrolyzing proteins into smaller peptides and amino acids. The release of soluble nitrogen is an indicator of proteins being broken down and one of the main proteolytic factors involved in the production of WSN is chymosin (Visser, 1977; Fox et al., 1995). It was important to measure the percentage of soluble nitrogen before incubation to determine the initial amount of nitrogen in the samples. Assuming that the samples had not been subjected to ripening conditions where enzymes can thrive and no proteolytic activity had been initiated, it was expected that both treatment groups would have the same initial percentage of water soluble nitrogen. However, after the initial percentages were reported, anomalies in the data were identified. Due to the inconsistency in the data, it was concluded that this initial values could not be entirely trusted to do a comparison with the results after the incubation period. Thus, it was determined to analyze the statistical results of only the data collected after incubation to try to identify significant differences between treatments and not the effect over a period of time. It may be suggested that this difference in initial values could be attributed to the samples themselves, it is possible that there was some variation between samples at the moment of preparation, addition of materials and handling that may have caused the slurries 
to have different properties. In addition, even though the rate of proteolysis was prevented before incubation by keeping the slurries at low temperatures, it is possible that the enzymatic activity after the addition of rennet and protease was not fully controlled and that had some effect on the \%WSN readings.

In the early stages of cheese making, low levels of water soluble nitrogen are expected because caseins have not been hydrolyzed by proteolytic enzymes into smaller peptides or amino acids, therefore they remain with their initial structure.

Tavaria et al. (2004) reported values of water soluble nitrogen in Serra da Estrela cheese around $11 \%$ at the time of manufacture and $43 \%$ after 180 days of ripening. Macedo and Malcata (1997) and Fernandez-Salguero and San Juan (1999) reported values between 33 and $34.6 \%$ for the same variety. These percentages may vary according to the type of cheese but the values obtained in this research before incubation do not show any consistency and the high values specially for the controls do not coincide with information found in other studies. Even after a long period of ripening and maturation, it is difficult to find values of WSN close to a $100 \%$. Thus, with this information, it was challenging to trust the data and analyze it statistically and predict a trend or reliable significant differences between treatments. For this reason the data reported before incubation as well as the controls in both treatment groups were discarded from the analysis.

The ANOVA study showed that even by removing the controls from the test the data did not meet the normality and equal variance assumptions. 
Subsequently, the data was analyzed again with a log transformation. Log transformations are commonly done to achieve normality and equal variance between treatments before using any kind of general linear model such as ANOVA. Figures 20 and 21 show the distribution of the data before and after the log transformation. The data in figure 20 shows a fan shaped distribution failing to meet the equal variance assumption. Figure 21 shows more equal variation.

Table 2 shows the p-values for each factor and interaction after the log transformation of the data None of the factors and interactions show a statistically significant effect on WSN ( $p>0.05)$. However, as discussed in chapter 2, section 2.7.3, a study carried by Shirashoji et al. (2010), reported that by increasing the concentration of SHMP, they were able to account for and increment the soluble nitrogen content which is an indicator of protein dispersion. The chelator effect was close to statistical significance $(p=0.075)$. This could open the possibility that proteolysis still happened to some degree and maybe the combination of the chelating agents with the protease revealed higher percentages of WSN than expected in a system with only one or the other component.

\subsubsection{Urea-PAGE electrophoresis}

The density of the bands in each gel was measured for every treatment. These differences were analyzed with ANOVA to identify the possible decrease in the percentage of each major casein. The gels were run by duplicate three times before and after incubation, testing the exact same samples in each 
treatment group. The samples analyzed before incubation were expected to have similar percentages since it was assumed that very little proteolysis had occurred at this stage. Yet, significant difference was found between samples before incubation. Appendices $C$ and D contain the ANOVA tables that show the $p$ values for both treatment groups as well as the ANOVA tables for samples tested before and after incubation.

This difference may be due to the fact that, contrary to what was expected, proteolysis did occur to some degree during sample preparation or holding time in water bath at $50^{\circ} \mathrm{C}$. It could be possible that this high temperature promoted some proteolytic activity, which is ideal for enzymes to hydrolyze proteins.

In chapter 6, section 6.2.2, it can be observed that tables 3, 5, and 7 show the ANOVA results for the difference between treatments before and after incubation. As the tables show, a statistical significant difference was identified for all caseins. These results may suggest that even if the statistical analysis for the \%WSN test did not reflect what was expected, and the treatments did not show any significant effect on \%WSN, it is possible that proteolysis occurred at some level even with the addition of chelating agents. For gamma casein only four levels were connected, SC $5 \mathrm{mM}$ with enzymes and SHMP $10 \mathrm{mM}$ with no enzyme marked with letter $B$, and the control with no enzyme and SC 25mM with enzyme marked with letter G. SHMP $10 \mathrm{mM}$ with no enzyme seems to reappear paired with the lower level of SHMP and both levels of SC with enzyme which shows that these treatments did not have a significantly different effect from one 
another $(p>0.05)$. There is no particular trend that shows if the pairs are connected the same for all three caseins. For certain treatments the difference is significant if we look at the enzyme and the treatment together. For instance, the percentage of gamma casein is affected in every treatment with the addition of enzyme. The square mean is higher for the treatments that include the enzyme except SHMP 2.5mM,yes which is smaller than SHMP $2.5 \mathrm{mM}$,no. for beta, the treatments had a decreasing effect in the percentage except for SC 5mM which does not find a difference between enzymes. For alpha casein, the control with enzyme and SHMP $2.5 \mathrm{mM}$, yes had a positive effect, both SC $5 \mathrm{mM}$ and SC $25 \mathrm{mM}$ had a higher mean without the absence of enzyme than with the presence of it. SHMP $10 \mathrm{mM}$ had the most negative change in the percentage of alpha but a difference for the enzyme cannot be identified. One of the reasons for the variation in the differences between treatments may be that the susceptibility to hydrolysis varies for every casein and, in the presence of a chelator. They might react differently to proteolytic activity. It is also possible that the way the chelator interacts with the caseins has an effect on how the enzymes act but it appears that the lower concentration levels of both chelators paired with other treatments seem to have no significant difference with and without enzymes as well as the higher concentrations of SHMP. This suggests that possibly working with a different concentration could be an option to measure proteolytic activity. For this reason it is strongly advised that for future research more specific methods are implemented to study and understand the interaction of caseins with one another 
and the effect of external factors such as chelating agents on the proteolytic activity of enzymes during ripening.

As discussed before, two studies were conducted to analyze the degradation of caseins, which could be translated as a decrease in the amount of nitrogen and in the percentage of caseins present in the samples. Kjeldahl procedures although widely used as an analytical method, might not be the most sensitive test for this experiment, therefore it is highly recommended to consider using complementary methods and identifying if the fragments released in the samples are small enough peptides to be detected with this procedure.

There was inconsistency and unusual behavior in the data for the WSN test. Yet significant differences were found in the Urea-PAGE gels, this creates doubts in the actual effects that chelating agents may have on proteolysis of caseins. If proteolysis is indeed occurring at some level and different bands are detected on Urea-PAGE gels, more specialized methods should be used to be able to identify what these bands represent. Knowing what components are present in each band may give us more information about the level or rate of proteolysis that is occurring in the presence of chelating agents and what kind of degradation products and being hydrolyzed. Methodologies and equipment such as high pressure liquid chromatography, to more accurately isolate and identify certain proteins and peptides may complement this method or be more useful to conduct this type of research as they provide more specific information about the particles involved. 


\section{Conclusions}

The findings of this research show that there was no particular trend in the data to demonstrate an effect of chelators on proteolysis that may have an impact on the amount of water soluble nitrogen being released in the micellar casein slurry. Although the test did not provide any significant difference, it does not necessarily mean that proteolysis did not occur in the system. There might be several reasons why no significant difference and proteolytic activity was detected in this part of the experiment. One reason could be that the method used was not sensitive enough to identify protein break down. It can also be possible that the rate of proteolysis occurring in the samples is not producing enough peptides or fragments soluble in water so they cannot be accounted for with this method. Although there was no relationship between the WSN test and the Urea-PAGE analysis that indicated that chelators affect the rate of proteolysis in some way, the electrophoretic gels did suggest some proteolytic activity. The peaks plotted with the image $\mathrm{J}$ software suggest the presence of caseins and possibly of other fragments as a result of protein degradation. The statistical analysis performed in this part of the experiment showed significant difference that partially supports the hypothesis of this study. These differences can be observed specially when looking at the chelating treatment and enzyme together.

The squared means in the Tukey's comparisons shows that a lot of the treatments combined with the enzyme had more positive or negative effects. Further research needs to be done in order to have a more profound 
understanding of to what extent proteolysis is happening under these conditions and if chelating agents are indeed affecting the rate of proteolysis in a way that can significantly improve its application in the development of flavor with a shorter aging period. By being able to identify the same biochemical events such as proteolysis that happen during cheese ripening in a system where no coagulation occurs it might be possible to open the opportunity to developing a liquid system that tastes and even smells like cheese but may have diverse technological applications. 


\section{REFERENCES}

Chitpinityol, S. \& Crabbe, MJC. (1998). Chymosin and aspartic proteinases. Food Chem., 61: 395-418.

Collins Y.F., McSweeney P.L.H., \& Wilkinson M.G. (2003). Lipolysis and free fatty acid catabolism in cheese: a review of current knowledge. International Dairy Journal, 13, pp. 841-866.

Delahunty C.M. \& Drake M.A. Sensory character of cheese and its evaluation, in: P.F. Fox, P.L.H. McSweeney, T.M. Cogan, T.P. Guinee. (2004). General aspects, Cheese: Chemistry, physics and microbiology (3rd ed.), Vol. 1, Elsevier Academic Press, London, UK (2004), pp. 455-487.

De Kort, J.P. Esther. (2012). Influence of calcium chelators on concentrated micellar casein solutions. From micellar structure to viscosity and heat stability. Thesis. Wageningen University. Pages 29.

De Kort, E.J.P., M. Minor, T.H.M. Snoeren, A.C.M. van Hooijdonk, \& E. van der Linden. (2009). Calcium binding capacity of organic and inorganic ortho- and polyphosphates. Dairy Science and Technology. 89: p. 283-299.

De Kruif, C.G. (1999). Casein micelle interactions. Int. Dairy J. 9:183-188.

Farrell, H.M., Jr., Jimenez-Flores, R., Bleck, G.T., Brown, E.M., Butler, J.E., Creamer, J.K., Hicks, C.I., Hollar, C.M., Ng-kwai-hang, K.F. \& Swaisgood, H.E. (2004). Nomenclature of the proteins of cows' milk - sixth revision. J. Dairy sci. 87, 1641-1674. 
Fernández-Salguero, J. \& Sanjuán E. (1999). Influence of vegetable and animal rennet on proteolysis during ripening in ewe's milk cheese. Food Cemistry, $64,177-183$.

Fox, P.F. and Kelly, A.L. (2006). Indigenous enzymes in milk: Overview and historical aspects -Part 1. Int. Dairy J.

Fox, P.F. \& Cogan, in: P.F. Fox, P.L.H. McSweeney, T.M. Cogan, T.P. Guinee. (2004). Factors that affect the quality of cheese. General aspects, Cheese: Chemistry, physics and microbiology (3rd ed.), Vol. 1, Elsevier Academic Press, London, UK, pp. 583-608

Fox P.F. (1992). Chemistry of the Caseins. Advanced Dairy Chemistry-1: Proteins, Elsevier, London, pp. 63-110.

Fox, P.F. (1989). Proteolysis During Cheese Manufacture and Ripening. J. Dairy Sci. 72:1379-1400. doi:10.3168/jds.S0022-0302(89)79246-8.

Gaucheron, F., The minerals of milk. Reproduction Nutrition Development, (2005). 45: p. 473-483.

Harper W. \& Kristoffersen. (1970). Biochemical aspects of flavor development in Cheddar cheese slurries. J. Agric. Food Chem., 18 (4), pp 563-566. DOI:10.1021/jf60170a008.

Holt, C., (1985). Chapter 6: The milk salts: their secretion, concentrations and physical chemistry, in Development in Dairy Chemistry - 3: Lactose and minor 
constituents, P.F. Fox, Editor. Elsevier Applied Science Publishers: London, UK. p. $143-181$.

Hurley, L. Walter. (2009). Milk composition and synthesis. University of Illinois, Urbana-Champaign.

Joha Guide. (1989). Processed cheese manufacture. BK Ladenburg. Pages 6373.

Johnston, D. E., \&. Murphy R. J. (1992). Effects of some calcium chelating agents on the physical properties of acid-set milk gels. J. Dairy Res. 59:197208.

Lucey, J. A., Johnson, M. E., \& Horne, D. S. (2003). Invited review: perspectives on the basis of the rheology and texture properties of cheese. Journal of Dairy Science, 86 2725-2743.

Macedo, A.C. \& Malcata, F.X. (1997). Secondary proteolysis in Serra cheese during ripening and throughout the cheese-making season. Zeitschrift für Lebensmittel Untersuchung und Forschung, 204, 173.179.

Makhal S., Giri A., \& Kanawjia S. (2013). Effect of k-carrageenan and tetrasodium pyrophosphate on the yield of direct acidified cottage cheese. Journal of Food Science and Technology. 50(6): 1200-1205.

McSweeney P.L.H.. (2004). Biochemistry of cheese ripening: introduction and overview,in: P.F. Fox (Ed.), General aspects, Cheese: Chemistry, physics and microbiology (3rd ed.), Vol. 1, Academic Press, London, UK, pp. 347360. 
Mekmene, O.,. Le Graet Y, \& Gaucheron F. (2009). A model for predicting salt equilibria in milk and mineral-enriched milks. Food Chemistry. 116: p. 233239. 39.

Mizuno, R., \& J. A. Lucey. 2007. Properties of milk protein gels formed by phosphates. J. Dairy Sci. 90:4524-4531.

Mizuno, R. \& J.A. Lucey, (2005). Effects of emulsifying salts on the turbidity and calcium-phosphate- protein interactions in casein micelles. Journal of Dairy Science. 88: p. 3070-3078.

Odagiri, S. \& T.A. Nickerson (1965). Complexing of calcium by hexametaphosphate oxalate, citrate and ethylenediamine-tetraacetate in milk. II. Dialysis of milk containing complexing agents. Journal of Dairy Science, 48: p. 19-22.

Odagiri, S. \& Nickerson T.A.. (1964). Chain length determination of polyphosphates. Journal of Dairy Science. 47: p. 920-921.

Odagiri, S. \& Nickerson. T.A. (1964). Complexing of calcium by hexametaphosphate, oxalate, citrate, and EDTA in milk. I. Effects of complexing agents of turbidity and rennet coagulation. Journal of Dairy Science. 47: p. 1306-1309. 
O’Mahony, J. A., Lucey J. A., \& McSweeney P. L. H. (2005). Chymosin-mediated proteolysis, calcium solubilization and texture development during ripening of Cheddar cheese. J. Dairy Sci. 88:3101-3114.

Panouillé, M., T. Nicolai, \& D. Durand. (2004). Heat induced aggregation and gelation of casein submicelles. International Dairy Journal. 14: p. 297-303.

Pitkowski, A., T. Nicolai, \& D. Durand. (2008). Scattering and turbidity study of the dissociation of casein by calcium chelation. Biomacromolecules. 9: p. 369-375.

P. Udabage, McKinnon I. R., \& Augustin M.A. (2001). Effects of mineral salts and calcium chelating agents on the gelation of renneted skim milk. J. Dairy Sci. 84: 1569-1575.

Schmidt D.G. (1982). Association of caseins and casein micelle structure. P.F. Fox, Developments in Dairy Chemistry, Applied Science Publishers, Barking, UK. pp. 61-86.

Shalabi, S. I., \& P.F. Fox. (1982). Influence of $\mathrm{pH}$ on the rennet coagulation of milk. J. Dairy Res. 49:153-157.

Smiddy, M.A., Martin J.-E.G.H., Kelly A.L., De Kruif C.G., \& Huppertz T. (2006). Stability of casein micelles cross-linked by transglutaminase. Journal of Dairy Science. 89: p. 1906-1914.

Turner, B.L., Paphazy M.J, Haygarth P.M., \& McKelvie I.D. (2002). Inositol phosphates in the environment. Philosophical Transactions of the Royal Society of London. Series B, Biological Sciences. 357: p. 449-469. 
Udabage, P., Mckinnon I. R., \& Augustin M.-A. (2000). Mineral and casein equilibrium in milk: Effects of added salts and calcium chelating agents. $J$. Dairy Res. 67:361-370.

Upreti, P., Buhlmann P., \& Metzger L.E. (2006). Influence of calcium and phosphorus, lactose and salt-to moisture ratio on cheddar cheese quality: $\mathrm{pH}$ buffering properties of cheese. Journal of Dairy science. 89: p. 938-950.

Vujicic, I., deMan J.M., \& Woodrow I.L. (1968). Interaction of polyphosphates and citrate with skimmilk proteins. Canadian Institute of Food Science and Technology Journal. 1: p. 17- 21.

Walstra Pieter. (1979). On the Stability of Casein Micelles. J Dairy Sci, 73.

Walstra Pieter. (1999). Casein sub-micelles: do they exist? Int Dairy J, 9, pp. 189-192. 


\section{APPENDICES}

Appendix A: Statistical analysis for \%WSN after incubation with controls

Table 9. ANOVA table for \%WSN before incubation with controls

\begin{tabular}{lrrr}
\hline Source & DF & F Ratio & Prob > F \\
Enzyme & 1 & 0.1725 & 0.6828 \\
Treatment & 4 & 1.0239 & 0.4216 \\
enzyme ${ }^{*}$ Treatment & 4 & 0.8678 & 0.5021 \\
\hline
\end{tabular}

Residual by Predicted Plot

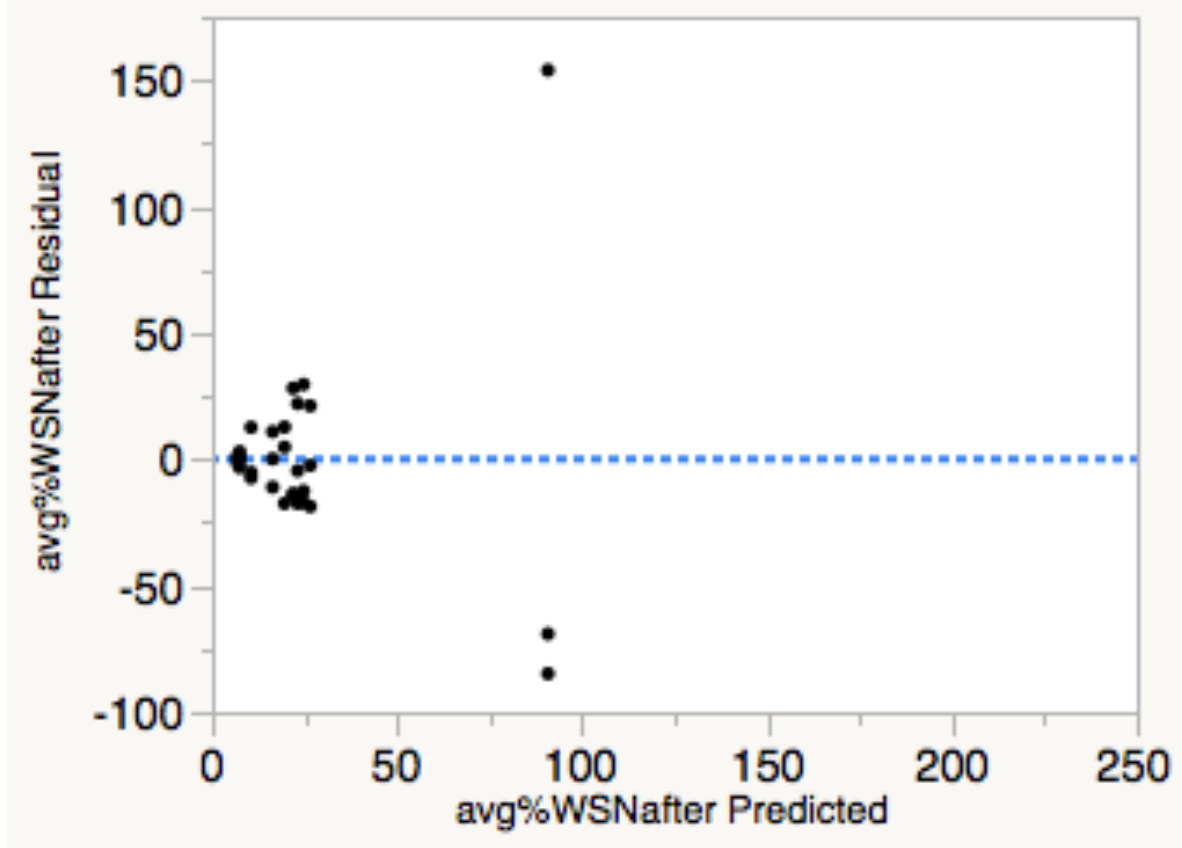


Appendix B: Statistical analysis for \%WSN after incubation with log transformation

Table 10. ANOVA table for \%WSN after incubation with controls and log transformation.

\begin{tabular}{lrrr}
\hline Source & DF & F Ratio & Prob > F \\
Treatment & 4 & 1.2071 & 0.3421 \\
Enzyme & 1 & 0.3083 & 0.5856 \\
enzyme*Treatment & 4 & 0.5525 & 0.6998 \\
\hline
\end{tabular}

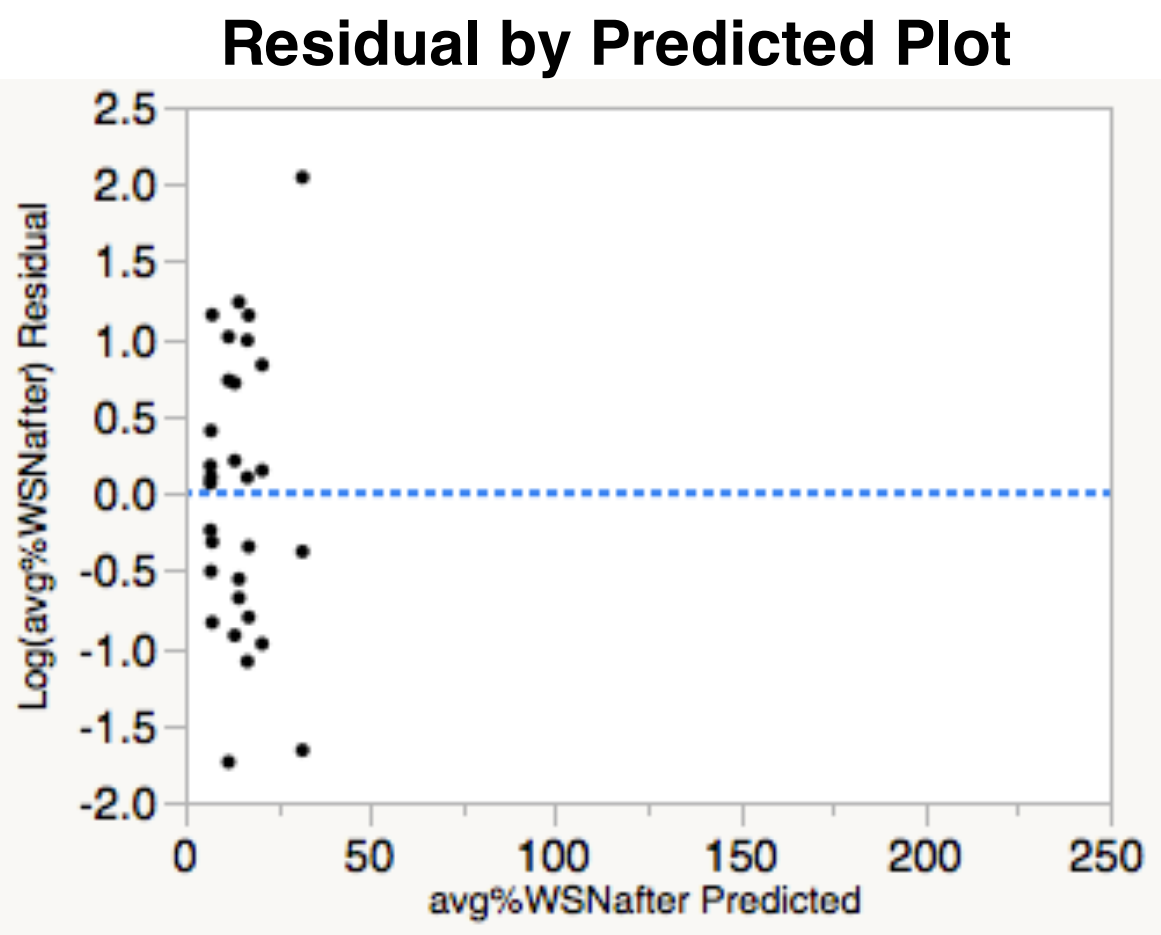


Appendix C: Statistical analysis for Urea-PAGE gels before incubation for percentage of gamma, beta and alpha caseins with controls

Table 11. ANOVA table for Urea-PAGE gels before incubation for percentage of gamma beta and alpha caseins with controls

\begin{tabular}{lrrr}
\hline Source & DF & F Ratio & Prob > F \\
treatment & 4 & 575343.4 & $<.0001^{*}$ \\
Enzyme & 1 & 2019.938 & $<.0001^{*}$ \\
treatment ${ }^{*}$ enzyme & 4 & 269078.8 & $<.0001^{*}$ \\
\hline
\end{tabular}

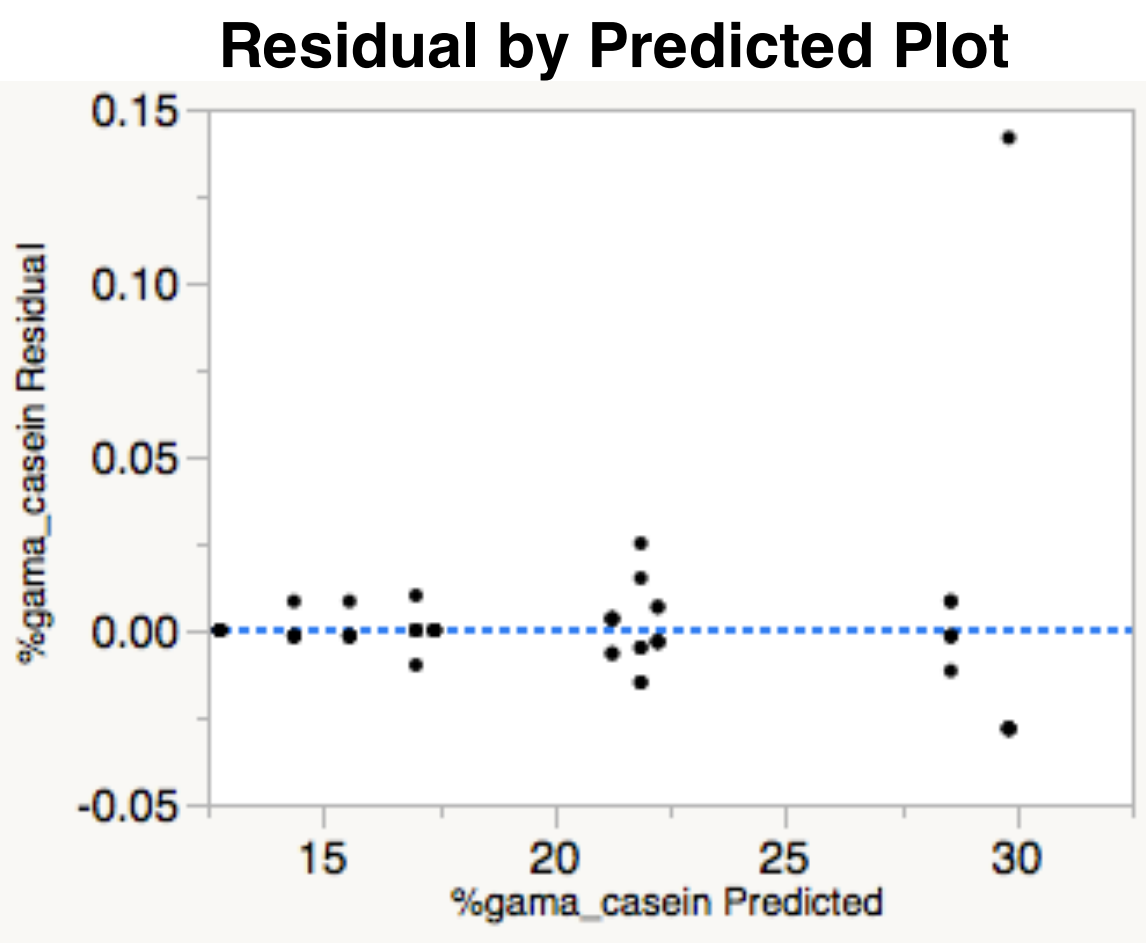


Table 12. ANOVA table for Urea-PAGE gels before incubation with controls for beta casein

\begin{tabular}{lrrr}
\hline Source & DF & F Ratio & Prob > F \\
treatment & 4 & 81107.91 & $<.0001^{*}$ \\
Enzyme & 1 & 281299.1 & $<.0001^{*}$ \\
treatment*enzyme & 4 & 103979.7 & $<.0001^{*}$ \\
\hline
\end{tabular}

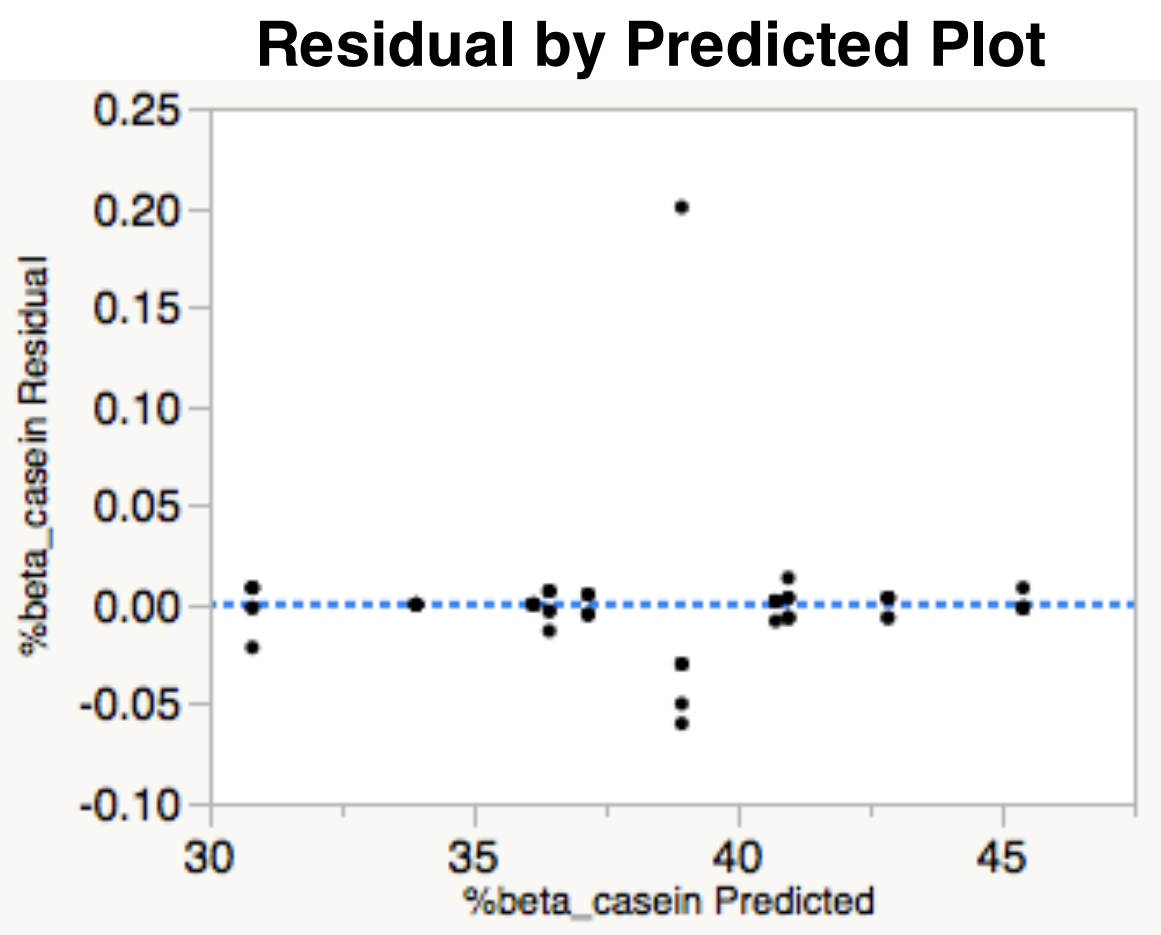


Table 13. ANOVA table for Urea-PAGE gels before incubation with controls for alpha casein

\begin{tabular}{lrrr}
\hline Source & DF & F Ratio & Prob > F \\
treatment & 4 & 152366.9 & $<.0001^{*}$ \\
Enzyme & 1 & 108941.7 & $<.0001^{*}$ \\
treatment ${ }^{*}$ enzyme & 4 & 35018.53 & $<.0001^{*}$ \\
\hline
\end{tabular}

\section{Residual by Predicted Plot}

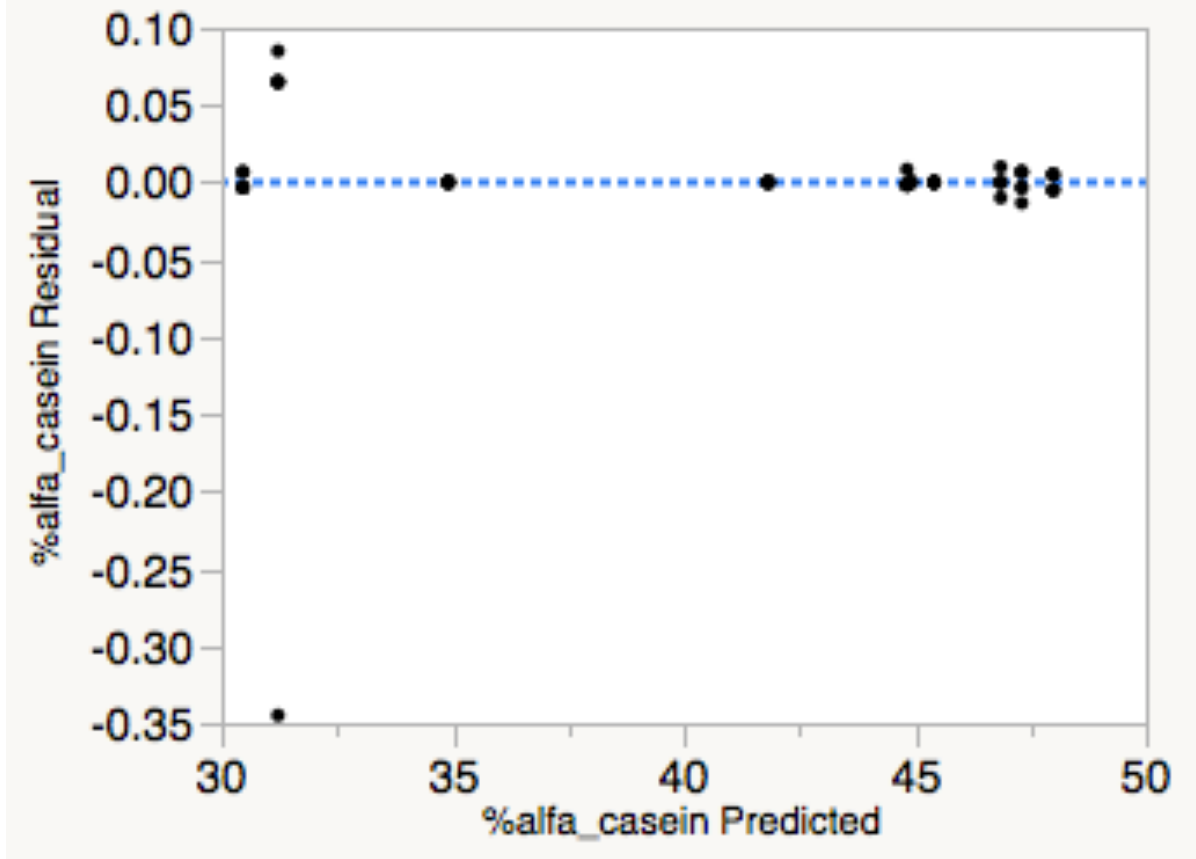


Appendix D: Statistical analysis for Urea-PAGE gels after incubation for percentage of gamma, beta and alpha caseins with controls

Table 14. ANOVA table for Urea-PAGE gels after incubation for percentage of gamma beta and alpha caseins with controls

\begin{tabular}{lrrr}
\hline Source & DF & F Ratio & Prob > F \\
Treatment & 4 & 2038.214 & $<.0001^{*}$ \\
Enzyme & 1 & 1807.706 & $<.0001^{*}$ \\
Treatment*enzyme & 4 & 1821.095 & $<.0001^{*}$ \\
\hline
\end{tabular}

Residual by Predicted Plot

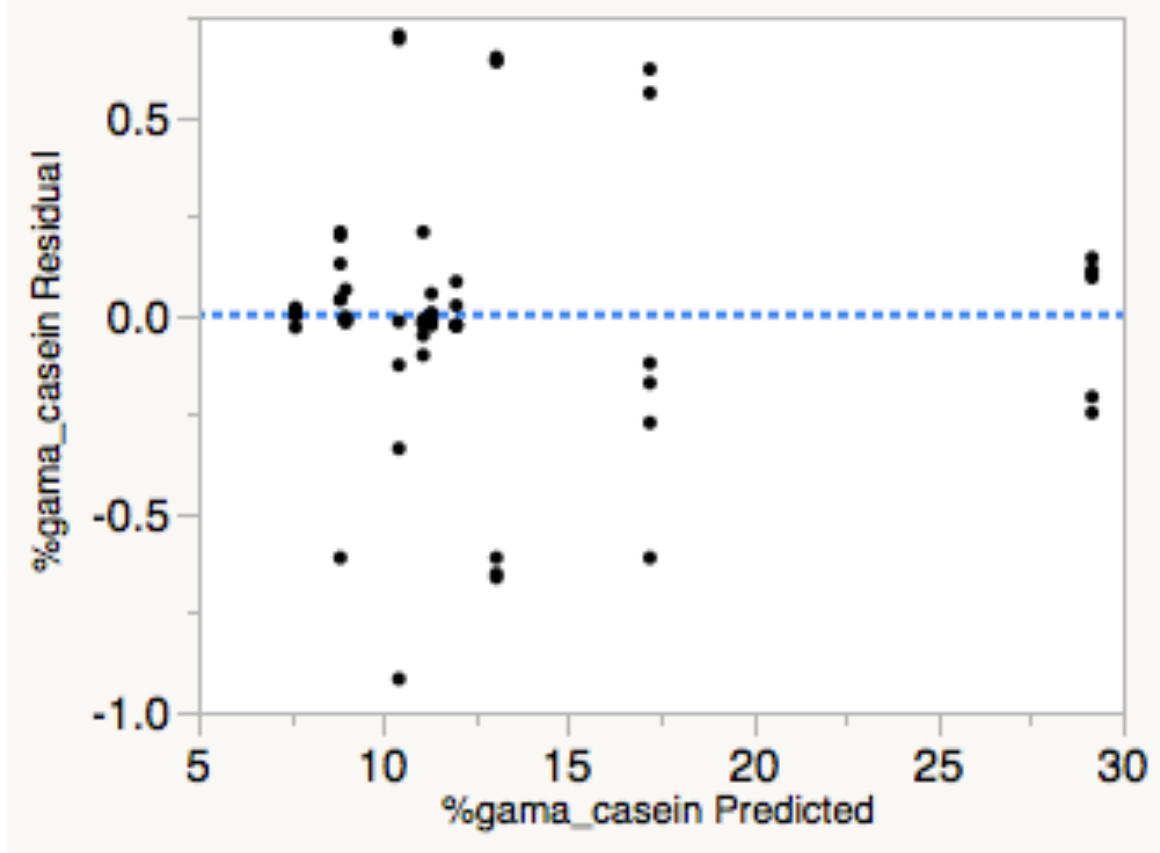


Table 15. ANOVA table for Urea-PAGE gels after incubation with controls for beta casein

\begin{tabular}{lrrr}
\hline Source & DF & F Ratio & Prob > F \\
Treatment & 4 & 178.3690 & $<.0001^{*}$ \\
Enzyme & 1 & 651.5933 & $<.0001^{*}$ \\
Treatment $^{*}$ enzyme & 4 & 28.3850 & $<.0001^{*}$ \\
\hline
\end{tabular}

Residual by Predicted Plot

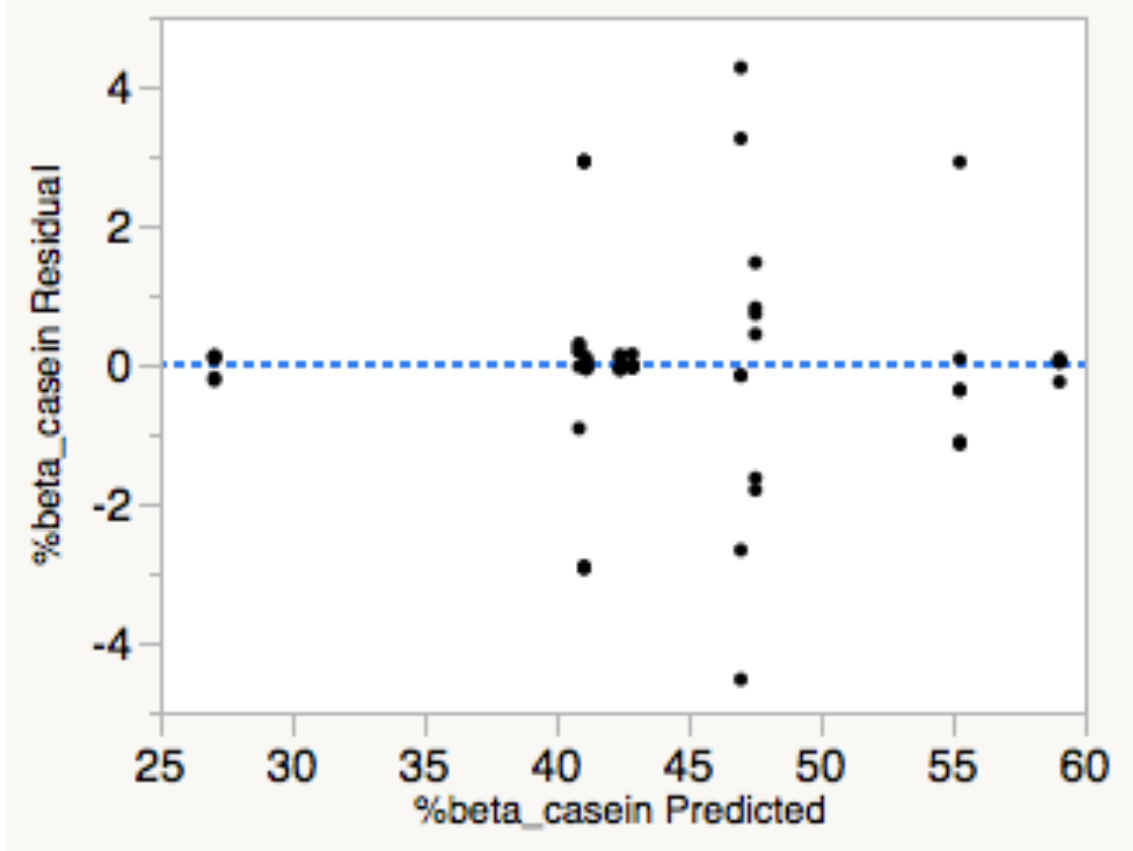


Table 16. ANOVA table for Urea-PAGE gels after incubation with controls for alpha casein

\begin{tabular}{lrrr}
\hline Source & DF & F Ratio & Prob > F \\
Treatment & 4 & 36.4709 & $<.0001^{*}$ \\
Enzyme & 1 & 331.9747 & $<.0001^{*}$ \\
Treatment enzyme & 4 & 68.6908 & $<.0001^{*}$ \\
\hline
\end{tabular}

\section{Residual by Predicted Plot}

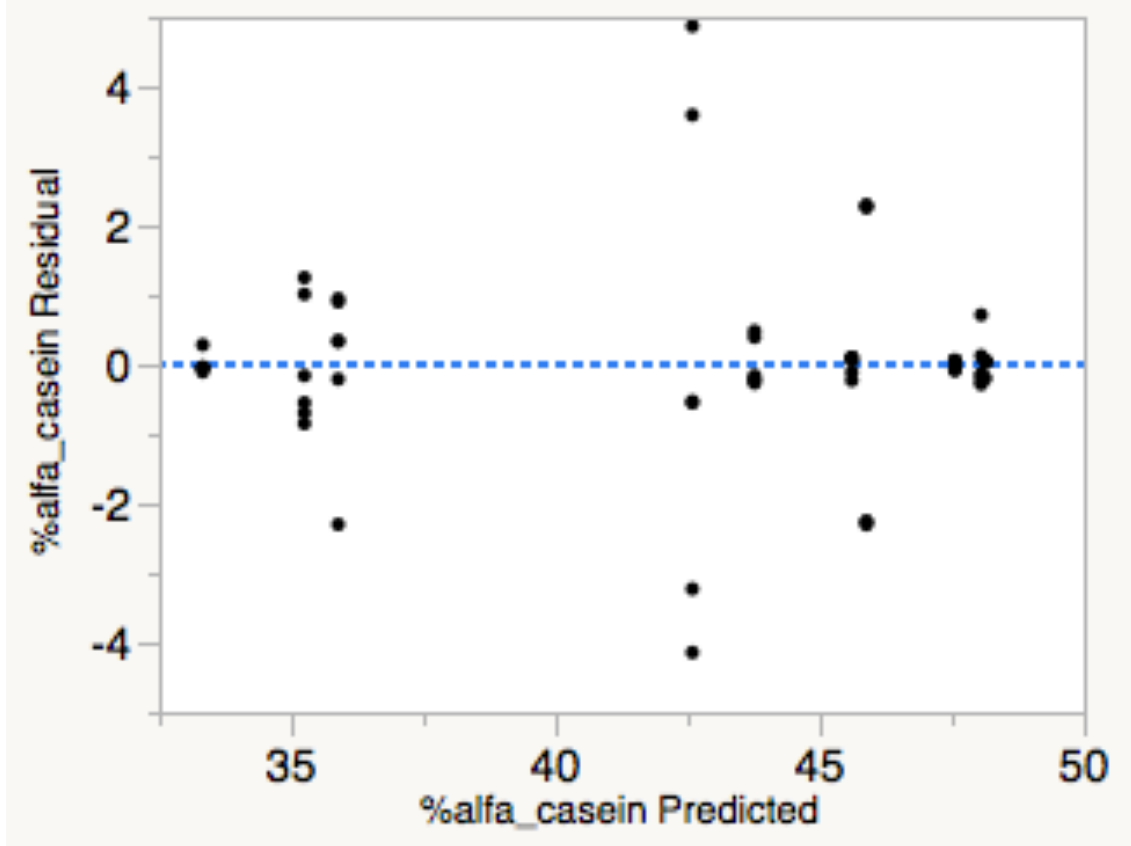


Appendix E: Statistical analysis for the percentage of gamma, beta and alpha caseins in Urea-PAGE gels before incubation without controls

Table 17. ANOVA for percentage of gamma casein before incubation without controls

\begin{tabular}{lrrr}
\hline Source & DF & F Ratio & Prob > F \\
Chelator & 1 & 16941.25 & $<.0001^{*}$ \\
Level & 1 & 80031.90 & $<.0001^{*}$ \\
Enzyme & 1 & 8935.289 & $<.0001^{*}$ \\
Chelator ${ }^{*}$ level & 1 & 1460006 & $<.0001^{*}$ \\
Chelator ${ }^{*}$ enzyme & 1 & 11378.22 & $<.0001^{*}$ \\
level $^{*}$ enzyme & 1 & 7794.312 & $<.0001^{*}$ \\
Chelator*level $^{*}$ enzyme & 1 & 848835.8 & $<.0001^{*}$ \\
\hline
\end{tabular}

Table 18. ANOVA for percentages of beta casein before incubation without controls

\begin{tabular}{lrrr}
\hline Source & DF & F Ratio & Prob > F \\
Chelator & 1 & 194167.8 & $<.0001^{*}$ \\
Level & 1 & 10205.10 & $<.0001^{*}$ \\
Enzyme & 1 & 272775.4 & $<.0001^{*}$ \\
Chelator*level & 1 & 3936.172 & $<.0001^{*}$ \\
Chelator ${ }^{*}$ enzyme & 1 & 95956.40 & $<.0001^{*}$ \\
level*enzyme $_{\text {Chelator*level*enzyme }}^{*}$ & 1 & 51895.98 & $<.0001^{*}$ \\
\hline
\end{tabular}

Table 19. ANOVA for percentages of alpha casein before incubation without Controls

\begin{tabular}{lrrr}
\hline Source & DF & F Ratio & Prob > F \\
Chelator & 1 & 41661.66 & $<.0001^{*}$ \\
Level & 1 & 3655.814 & $<.0001^{*}$ \\
Enzyme & 1 & 120602.7 & $<.0001^{*}$ \\
Chelator*level & 1 & 301859.2 & $<.0001^{*}$ \\
Chelator*enzyme & 1 & 18810.04 & $<.0001^{*}$ \\
level*enzyme $_{\text {Chelator*level }^{*} \text { enzyme }}$ & 1 & 29386.56 & $<.0001^{*}$ \\
\hline
\end{tabular}


Appendix F: Statistical analysis for the difference in percentage of gamma, beta and alpha caseins in Urea-PAGE gels before and after incubation without controls

Table 20. ANOVA for the difference in percentage of gamma casein before and after incubation without controls

\begin{tabular}{lrrr}
\hline Source & DF & F Ratio & Prob > F \\
Chelator & 1 & 6440.479 & $<.0001^{*}$ \\
Level & 1 & 535.8876 & $<.0001^{*}$ \\
Enzyme & 1 & 2763.580 & $<.0001^{*}$ \\
Chelator level & 1 & 14872.99 & $<.0001^{*}$ \\
Chelator*enzyme & 1 & 484.8705 & $<.0001^{*}$ \\
level $^{*}$ enzyme $_{\text {Chelator }^{*} \text { level }}^{*}$ enzyme & 1 & 3554.676 & $<.0001^{*}$ \\
\hline
\end{tabular}

Table 21. ANOVA for the difference in percentage of beta casein before and after incubation without controls

\begin{tabular}{lrrr}
\hline Source & DF & F Ratio & Prob > F \\
Chelator & 1 & 86.0927 & $<.0001^{*}$ \\
Level & 1 & 429.3175 & $<.0001^{*}$ \\
Enzyme & 1 & 165.0489 & $<.0001^{*}$ \\
Chelator*level & 1 & 13.7176 & $0.0007^{*}$ \\
Chelator*enzyme & 1 & 105.4476 & $<.0001^{*}$ \\
level*enzyme $_{\text {Chelator*level*enzyme }}^{*}$ & 1 & 24.9256 & $<.0001^{*}$ \\
\hline
\end{tabular}

Table 22. ANOVA for the difference in percentage of alpha casein before and after incubation without controls

\begin{tabular}{lrrr}
\hline Source & DF & F Ratio & Prob $>$ F \\
Chelator & 1 & 73.8275 & $<.0001^{*}$ \\
Level & 1 & 245.7358 & $<.0001^{*}$ \\
Enzyme & 1 & 1.3980 & 0.2450 \\
Chelator*level & 1 & 553.0726 & $<.0001^{*}$ \\
Chelator ${ }^{*}$ enzyme & 1 & 232.5927 & $<.0001^{*}$ \\
level $^{*}$ enzyme & 1 & 68.8195 & $<.0001^{*}$ \\
Chelator*level*enzyme $^{*}$ & 1 & 22.8046 & $<.0001^{*}$ \\
\hline
\end{tabular}

